\title{
CORRESPONDENCIA LITERARIA (1791-1803) DEL ARABISTA JOSE ANTONIO BANQUERI CON DON FR. MANUEL DO CENACULO VILAS BOAS, OBISPO DE BEJA Y ARZOBISPO DE EVORA*
}

I

Madrid 24 de Mayo de 1791

Excmo. Señor Obispo de Beja:

Mi más amado y venerable favorecedor y protector: Después de tanto tiempo de silencio busca a V. Excia. su afectísimo humilde Banqueri, quien siempre le ha tenido y tendrá en la memoria y en el corazón. Mi natural encogimiento por una parte, y por otra el tener noticias de la salud de V. Excia., unas veces por nuestro Sousa y otras por mi amado Maestro el Rvdmo. Fr. Rafael antes de su desgracia, fueron la causa verdadera de haber guardado yo tan largo silencio. Después, esta misma desgracia y ruina de los Padres, el desmantelamiento de mi Provincia con otros desastres ulteriores ocurridos en ella, me obligaron a no molestar a V. Excia. con cartas melancólicas, que necesariamente habían de ir marcadas con el sello de la aflicción que me oprimía, y aún oprime mi corazón. Con todo, esperaba hacerlo con la extensión correspondiente después de sosegada la tormenta, después de tranquilizado algún tanto mi espíritu, y después de disipados los muchos y varios motivos que aún yo tenía para temer (no obstante mi segregación del Cuerpo) ya de parte de unos falsos hermanos que tan cruelmente se habían ensagrentado contra unos hombres tan religiosos y tan beneméritos de su Orden y de la Patria; y ya de parte de un Superior seducido (no sé si diga voluntariamente) por sus mismos émulos, y acaso también instruido para intentar y ejecutar tal ruina por algún magnate de aquí (como algunos han presumido), animado del espíritu de parcialidad o de otra baja pasión indigna de las almas grandes, generosas y nobles... Pero, ¿a dónde me lleva mi vivo sentimiento, el cual parece ha de estar 
hiriendo mi corazón perpetuamente? Permítame V. Excia. este desahogo, y perdone con benignidad esta queja de un corazón duramente lastimado. No digo más en este punto por no incurrir en lo mismo que temía antes, y me obligaba a no escribir a V. Excia. No renueve yo llagas, aunque para mi bien recientes y que sólo largos años pueden cicatrizar. Tal ha sido el verdadero motivo de mi silencio violento a que me había abandonado persuadido de que la penetración y prudencia de V. Excia. se haría cargo de la legítima causa de él, y que su bondad no lo atribuirá a olvido ni menos a ingratitud.

Asimismo esperaba para escribir a V. Excia. con la satisfacción de darle noticias que le fuesen más lisongeras y agradables, poderle informar de algún feliz resultado de mis trabajos y tareas, como esperaba. Pero viendo que esta esperanza se va dilatando demasiado y quizá nunca llegará a cumplirse, no es razón prolongar más mi silencio, aunque sea preciso romperle por una ingrata relación de mi situación pasada y actual.

Aunque el objeto de mi venida y la de Jiménez a Madrid por el año de 1779 fue principalmente sobre negocios de la Provincia respectivos a la sedición que Fr. Domingo de Herrera, Luque y consortes levantaron contra los PP. Mohedanos, no omití desde luego dedicar los ratos libres en adelantar al lado de Don Miguel Casiri los buenos principios del árabe que adquirí en Lisboa. Mi tal cual aplicación enamoró a Casiri, y le movió a hacer gestiones a mi favor con los Excmos. Sres. Condes de Campomanes y Floridablanca; y así el primero me proporcionó el honor de hacerme Académico de la Historia, y el segundo hizo se me agregase a la Real Biblioteca en Plaza supernumeraria de oficial con el sueldo de 500 ducados (de que entonces di parte a V. Excia.). En vista de lo cual ya se echa de ver que ninguna parte tuvo el Sr. Bayer en mi destino, y que todo fue obra de Casiri. Desde aquel tiempo me dediqué con más tesón a adelantar la traducción principiada del Código Arábigo de Agricultura. Pero como mi destino y obligación era trabajar en mi posada y no en la Biblioteca, no podía usar en ésta de los libros que necesitaba, y debía tener siempre a la mano, como eran entre otros los Diccionarios de Menischi ${ }^{1}$ y de Giggeo $^{2}$ (de que carecía y aún carezco», y especialmente algunos códices arábigos que, aunque propios del Escorial, se hallaban en esta Biblioteca. Hice pretensiones repetidas con el Sr. Bayer para que se me entregasen estos Códices, y sólo conseguí me entretuviese con largas esperanzas, diciéndome que en saliendo de tales y cuales ocupaciones, se buscarían y se me entregarían. ¡Pretextos vanos!, pues nada tenía que hacer en esto más que dar comisión para ello a Casiri. En estas demoras pasaron dos años con no poco perjuicio 
del adelantamiento de mi traducción, hasta que desengañado y aun persuadido de algunas personas celosas, puse Memorial al Rey suplicando a Su Magestad mandase a su Real Biblioteca entregarme dichos Códices; lo cual no ejecuté hasta que el Sr. Bayer marchó a Valencia, por evitar que dijese que usaba para él de medios violentos. Al punto bajó orden al Decano que mandaba en su ausencia, y por el mismo se me entregaron los Códices que necesitaba. No crea V. Excia. que desde el momento que pertenecí a la Biblioteca dejare yo de procurar ganarme la benevolencia de este Señor empleando aquellos medios que a quien se tenga por celoso del adelantamiento de las letras le parecerían los más oportunos y ef ectivos; tales eran dar frecuentemente a su Iltma. cuenta del estado de mis trabajos, mostrarle deseo de que leyese algunos pasos de mi difícil traducción, con el fin de que me dijese si iba bien o mal desempeñada, etc. Pero lo primero siempre lo oyó con la más alta y fría indiferencia, y a lo segundo siempre respondía que bien, que ya; que después me avisaría, cuando estuviese desocupado. Lo que no parece haberse verificado todavía.

Después del pasaje de los Códices (de que nunca se me dio por entendido el Sr. Bayer) le supliqué varias veces mandase entregarme el Avicena arábigo-latino ${ }^{3}$, libro que absolutamente necesitaba para poder fijar algunas especies de plantas, cuyos nombres no se hallaban en los Diccionarios arábigos comunes. No conseguí que se me entregase el de la Biblioteca, y sólo me dio después de largo tiempo el puro original arábigo, que según dijo era de su propiedad; cuyo libro me hizo volver dentro de pocos días con el pretexto de que debía remitirlo a Valencia para uso de aquella Escuela; lo que dudo se haya verificado, habiendo yo visto el mismo libro en su casa más de un año después. ¿Es esto fomentar y promover los trabajos literarios ${ }^{4}$.

En medio de estos apuros y dificultades insuperables era yo alentado por algunas personas celosas, y aun por el mismo Ministro de Estado, quien hasta cierto tiempo mostró vivos deseos de que mi obra se adelantase, y así me lo daba a entender siempre que me presentaba a Su Excia. Después ya comencé a advertir en esto alguna novedad; de lo cual infería yo no poder ser otra la causa que el haber caído los RR. PP. Mohedanos de la gracia del Rvdmo. Salinas, concuñado de dicho Ministro. Desalentado yo así por todas partes, y en medio de los disgustos y temores que me cercaban por las desgracias de los Padres y de mis amados condiscípulos, concluí la primera parte de mi traducción en un tomo de 250 pliegos (comprendida la copia del texto) por abril de 1789. Cuya obra presentada al Ministro bajo orden del Rey a Casiri para que la examinase y juzgase, después de hecho el cotejo 
con el original con asistencia mía. Gastóse tres meses en este cotejo y revisión, y dicho Casiri informó muy favorablemente. Ya han pasado dos años, y ni la obra se imprime, ni yo recojo el fruto de mi trabajo, of recido desde el principio, y necesario e indispensable para adelantar en semejante ramo de erudición. Sin libros es imposible trabajar. Casiri me comunicaba su instrucción generosamente deseoso de dejar después de sus días un amado discípulo que le sucediese en su plaza de Bibliotecario. Pero el 12 de marzo de este mismo año murió con el desconsuelo de ver mi triste situación y conocer por ella que serían vanas sus esperanzas ${ }^{5}$.

Aquí es de advertir que desde que el P. Salinas se declaró acérrimo contrario de los Padres, o más bien desde el penúltimo Capítulo en que salió Soria de Provincial, y en el que el P. Fr. Rafael sufrió grandes e indecibles desaires, se hicieron venir por el Ministro dos personas de Oriente, el uno secular para interpretar la lengua turca, y el otro eclesiástico para suceder a Casiri en los dos empleos de intérprete y Bibliotecario (el cual es de creer que no lo será en sus trabajos $)^{6}$. En este caso, al parecer decisivo, llegué a entender, que ya no me quedaba otro recurso que pedir mi retiro y restituirme a mi Provincia. Comunicado este pensamiento con personas prudentes, los más reprobaban esta resolución por conocer que había yo de ser allí sacrificado, como lo han sido algunos de mis compañeros. Esto mismo conozco yo; pues la razón de haber sido discípulo de los Padres es para los Superiores actuales de la Provincia un pecado irremisible, a no contraer (como algún otro) el indigno mérito de serles infiel e infamar la buena memoria del ilustre perseguido difunto.

Pareciendo pues que en cualquier hipótesis de permanecer aquí o de retirarme, convendría solicitar alguna condecoración que equivaliese al sacrificio hecho de mi carrera y ascensos en el cuerpo, me valí del favor del Sr. Campomanes, quien gustoso me recomendó al nuevo Rvdmo. Comisario General el P. Fr. Joaquín Company, solicitando para mí la Definición General que quedó vacante por la segregación de esa Provincia y su erección en Congregación nacional independiente ${ }^{7}$. El P. Company dio palabra a Su Excia. de acceder a su alta recomendación, cuando se trate de proveer otras dos o tres Definiciones que hay vacantes pertenecientes a la Observancia. El Sr. Campomanes dejó ya de ser Gobernador del Consejo, y así no sé qué efecto podrá tener en lo sucesivo su recomendación. Es cierto que el Rvdmo. me manifiesta estimación en prueba de lo cual no ha dejado Su Rvdma. de darme alguna comisión, como es examinar la primera de varias obras que ha dejado manuscritas una Monja franciscana de Salamanca (de cuyo ligero y superficial informe remitiré copia a V. Excia. luego que tenga 
tiempo de hacerla), y también de ir formando a ratos perdidos un Plan de Estudios para reformar los de esta Familia (bien que de esta última comisión no ha vuelto Su Rvdma. a decirme nada, ni sé si instará en su proyecto de tal reforma ${ }^{8}$. Tal es la condecoración y tales los auxilios que se me proporcionan y dispensan para poder adelantar los costosos y duros trabajos de mi principal obligación y destino, en medio de hallarme sólo para todo, aún para lo material de la economía doméstica.

Pero volvamos a mi obra presentada. Varios amigos que la han registrado desean se publique, conociendo su utilidad. Los cuales viendo el aspecto nada favorable para esperar que esto se verifique, no han dejado de instarme a que me proporcione por medio de los finos y poderosos protectores que tendré en Portugal la alta recomendación de la Reina Fidelísima o de la Princesa del Brasil, a efecto de que se me confiera (no sólo para costear la impresión, mas también para adelantar mis trabajos) una competente pensión eclesiástica con Plaza de Bibliotecario. Para esto debí escribir a V. Excia. tiempo ha. Pero mi genio demasiado encogido me retraía de hacerlo, temiendo molestar o importunar a V. Excia. Así, sólo me propuse escribir a nuestro Sousa, rogándole hiciese cuanto le fuese posible en el particular, consultando primero con V. Excia. El contesta diciendo que no tiene arbitrio, ni aun por el Ministro de Marina, de quien depende como intérprete de la Corona. Que escriba yo a V. Excia. sin reparo ni encogimiento, persuadido de la especial benevolencia que le debo; añadiendo que sólo V. Excia. es quien puede proporcionarme la alta recomendación que necesito, y sacarme así del apuro en que me hallo. No dejo de conocer que no hallándose V. Excia. en Lisboa, no le será esto tan fácil. Pero también sé la grande y justa estimación que ha hecho y hace de la persona de $\mathrm{V}$. Excia. la Reina Fidelísima; y que a lo menos por medio del P. Felipe Scío (quien también sé que es íntimo amigo de V. Excia.) acaso se podrá hacer algo en el asunto ${ }^{9}$. Mas V. Excia. sabe mejor lo que conviene, y se debe hacer. Así, sólo insinúo aquí a V. Excia. que si a V. Excia. debí principalmente este mi primer establecimiento, a V. Excia. parece regular que deba yo también el complemento y perfección de su propia obra.

Participo a V. Excia. que el nuevo Presidente de Castilla, el Excmo. Sr. Conde de Cifuentes, es mi antiguo favorecedor; y que habiendo hecho conversación de V. Excia. he tenido la gran satisfacción de oírle expresiones propias de un amigo el más fino y afectuoso, con los elogios que V. Excia. por tantos títulos se merece. Este Sr. está en favorecerme. Pero algunas circunstancias políticas no permiten interesarlo ahora en este primer paso ${ }^{10}$. 
Ruego a V. Excia. rinda todos mis respetos a mi Rvdmo. y Sr. amigo su digno hermano con muchas saudades, y también a los Señores de mi antiguo conocimiento y afecto, que acompañen a V. Excia.

Excmo. Señor, B.l.m. a V. Excia. su más af ecto, obligado servidor y capellán,

$$
\text { Fr. José Banqueri }
$$

P.D.

Cuando V. Excia. tuviere que mandarme, quisiere honrarme con sus apreciables letras, vendrá el sobre: «A Don José Suárez de Toledo: Subida a los Angeles, frente la Casa de las Conchas, número 2 ». Basta una cubierta.

Excmo. Sr. Obispo de Beja, Don Fr. Manuel Cenáculo Vilas Boas.

\section{NOTAS}

1 Thesaurus Linguarum Orientalium Turcicae, Arabicae, Persicae, praecipuas earum opes a Turcis peculiariter usurpatas continens nimirum Lexicom Turcico-Arabico-Persicum Non solum vocum tam simplicium quam conjunctarum copia maxima refertum, sed etiam innumeris phrasithts tocupletatum, Quarum Quae Turcis usitatae am communis usis stont. Latine, Germunice, Italion. Gallice, Polonice: quae non adeo tulgares, in libris tamen et likeris non infrecuentes, Latine et Italice; quae porro rarins in usunt veniunt, nec nishi in libris profundioris. doctringe inveniuntur, Latine tantum expliantur et Grammaticam. Turcicam Cum adjectis ad shingula ejus rapita Proceptis Grammaticis Arabicue et Persicae lingure Opts Interpretibus practipuae, atissoue earumdem linguarum studiosis ad intelligentum omne genus Literarum Librorumqute apprime utike ac necessaritm Doctis quidem in compedium laboris, Tyronibus vero in manuductionem ad illas lingaus concinnatum, ar non tanum ex usu, sed ex probutissimis quibusque Orientis Autoribus collectum et in lucem editum Opera, typis, et sumptibus Francisci a Mesgnien Meninshi SS. Sep. Equitis Hierosolymitani, Sac. Caes. Majest. Consiliturii, ac linguarum Orientalium Interpretis primarii. Cum Gratia et Privilegio Sacrae Caesareae Majestatis. Viennae Austriae, MDCLXXX.

Durante estos mismos años parece ser que se había tenido en Madrid el proyecto de reimprimir dicha obra, pero tales intentos cesaron al tenerse noticia de que no sólo en Holanda se tenía el mismo propósito, sino que incluso ya se había impreso el primer volumen. En 1791 Cenáculo animaba a $F$ r. Juan de Sousa para que la comprase, y así éste lo deseaba hacer, pero no podía adquirirla debido a su elevado precio. A pesar de ello vemos cómo en el año 1794 estaba esperando un ejemplar que había comprado a un coste de 220.000 reis, sin contar la comisión. Conf. Joaquim Figanier, o. c., págs. 214, 246, 254.

2 Kanz al-lugat al-arabiyya Sive Thesaurus Linguae Arabicae quem Antonius Giggeius Mediolanensis S. Theol., et Collegii Ambrosiani Doctor Ex monumentis Arabum manuscriptis, et impressis Bibliothecae Ambrosianae eruit, concinnavit, Latini iuris, ac in Quatuor Volumina distribuit. Auspiciis, et liberalitate aeternae memoriae Federici Borromaei Cardinalis, et Ar. chiepisc. Mediol Eiusdem Bibliothecae, et Collegii Ambrosiani Instiutoris. Volumen Primum. Cum Privilegio. Mediolani. Ex Ambrosiani Collegii Typographia. M.DC.XXXII. Excudebat Jounnes Petrus Ramellatus Typographus linguarum Externarum. Superiorum permissu. 
3 No es fácil precisar con exactitud a qué obra de Avicenna se refiere. La profesora Marie Thérese d’Alverny, destacada conocedora del filósofo musulmán, respondiendo amablemente a nuestra solicitud de ayuda así nos lo confirma, pero cree que dado el interés de Banqueri por traducir una obra de agricultura, es posible que se esté refiriendo al famoso Canon de la medicina, traducido del árabe al latín por Gerardo de Cremona en Toledo, durante la segunda mitad del siglo XII. En la segunda parte de esta extensa obra se encuentra un largo capítulo acerca de los medicamentos simples, en el que se trata de las plantas. Gerardo de Cremona parece haber conservado el orden alfabético árabe, por lo cual titula el primer capítulo De littera alif, y así sucesivamente. En la mayor parte de los manuscritos que se conservan del Canon se encuentra un léxico intitulado Synonyma Avicennae, en el que las palabras árabes, algunas de las cuales son de origen griego, están explicadas en latín. En la Biblioteca Nacional de Madrid se encuentran varias ediciones y manuscritos de esta famosa obra.

4 Estas noticias sohre la actitud mantenida hacia Banqueri por parte de Pérez Bayer, dejan malparada la pretendida exaltación que este último hacía de sus proyectos a Fr. Juan de Sousa, durante su estancia en Madrid en febrero de 1786. El mismo Sousa, refiriéndose a la manifestación que Bayer le había hecho de sus proyectos, escribía a Cenáculo lo siguiente: "Elle me fez huna expressâo muito celebre, dizendo, que se chegar a arder o montâo de lenha que tem ajuntado, Deus nos acudu». Conf. J. Figanier, ob. cit., pág. 214. Durante un viaje suyo a Portugal en 1782, Pérez Bayer había sido objeto de las más finas atenciones por parte de Cenáculo y de los terceros portugueses, como el mismo Pérez Bayer dejó anotado en el diario que llevó de aquellas jornadas, publicado por José Leite de Vasconcelos en $O$ Archeologo Português, XXIV (1919-1920), págs. 108-176.

5 Esta fecha indicada por Banqueri y que repite en el Discurso preliminar de su traducción del Libro de Agricultura, págs. 12-13, contradice lo afirmado por Miguel Breydy, el cual pone la fecha del fallecimiento de Casiri el 19 de noviembre de 1792. Conf. "Labor de dos Maronitas acerca de la Arábiga-Hispana Escurialense», en El Concilio de Braga y la función de la legislación particular en la Iglesia (Salamanca: C.S.I.C.; Institulo Raimundo de Peñafort, 1975), pág. 174.

6 Este eclesiástico al que se refiere Banqueri es don Elias Scidiac, del cual habla Pérez Bayer en su Memorial del 12 de junio de 1791 al conde de Floridablanca. El intérprete secular de lengua turca tal vez sea Ignacio Schvertaczky. De ser así, es equivocada la apreciación de Figanier, el cual identifica a los dos en un solo personaje. Ob. cit., págs. 93-94, nota.

7 Como ya hemos señalado en otro lugar, los terceros portugueses se habían separado de la obediencia del Ministro General de la Observancia en 1780, constituyéndose a partir de entonces en Congregación nacional independiente. Habían perdido, por tanto, su derecho a continuar teniendo un Definidor General, puesto que al quedar vacante pasaba a corresponderle a los terceros españoles y que Banqueri pretendía para sí.

- El valenciano Fr. Joaquín Company había sucedido a Salinas en el cargo de Comisario General en diciembre de 1779. Con motivo del fallecimiento el 5 de junio de 1791 del Rydmo. P. Pascual Frosconi de Viareggio, Ministro General de la Observancia, Company fue nombrado su sucesor un año después, continuando en el desempeño del cargo hasta 1806, a pesar de haber sido nombrado arzobispo de Zaragoza en 1797. No sabemos que durante su gobierno de la Orden como Comisario o como Ministro General, Company hubiese publicado algún plan de estudios; tan sólo conocemos una Circular suya del 22 de julio de 1792 sobre la reforma de la Orden, en la cual señalaba como medio para conseguir dicha reforma la selección de Ios candidatos y la buena educación de los mismos, dentro de la línea ya señalada en los Capítulos de Mantua y de Valencia. 
9 Sobre las relaciones de Cenáculo con el escolapio P. Felipe Scío de San Miguel, puede verse nuestro artículo «Correspondencia del P. Felipe Scío de San Miguel con el obispo de Beja (Portugal) Fr. Manuel del Cenáculo Vilas Boas (1787-1795)», en Studium Ovetense, VIII (1980), págs. 237-262.

10 Don Juan de Silva y Meneses, conde de Cifuentes, había servido como embajador de España en Lisboa entre mayo de 1789 y septiembre de 1790. Acerca de su desempeño al frente del Consejo han escrito una pequeña monografía P. Ortega Costa y Ana María García Osma, Presidencia del Conde de Cifuentes, 1791 (Madrid, 1969). Falleció el 2 de marzo de 1792. Una carta suya a Cenáculo, en la que agradece la felicitación enviada con motivo de su nombramiento para la Presidencia del Consejo, en la B.P.E., Cod. CXXVII/1-6, fol. 320-320v.

\section{Excmo. Señor Obispo de Beja}

Muy Señor mío de todo mi afecto y estimación: Por nuestro Sousa habrá sabido la causa de mi silencio. Aún no he convalecido perfectamente de mis indisposiciones a la cabeza, de manera que aún permanece no poco débil sin permitir los fuertes trabajos. Sé los que ha sufrido y sufre V. Excia. en el establecimiento de esa Iglesia, y que a pesar de su activo celo y porfiados conatos, no ha logrado todavía ver cumplidos todos sus deseos. Desgracia es, que sólo los buenos establecimientos hay an de sufrir estorbos y oposiciones. Los Cuidados Literarios (que he estimado mucho, y he leído no sólo con gusto, sino también con aprovechamiento) es una obra inmortal por su vasta erudición, y un monumento eterno del celo pastoral de V. Excia. ${ }^{9}$ 9 Oh, si lograra la Iglesia de Dios muchos Prelados de igual celo! La Divina Magestad premie a V. Excia. no sólo el gran bien que ha hecho y sigue haciendo a esa dichosa Iglesia, sino también el ejemplo que da a los Príncipes de las otras. Pero la lástima es que son bien pocos los que imitan tales ejemplos.

He sabido por nuestro Sousa el bello Capítulo de esa Congregación, y cada vez admiro más la ingratitud y separación de los que V. Excia. atendió y favoreció con preferencia a otros que acaso habrían sido más agradecidos. El Sánchez, autor del tratadito sobre la Religión, fue uno de los más infieles a los PP. Mohedanos, y de los que más contribuyeron a su desgracia y ruina $^{2}$. Al contrario, mi compañero Jiménez permaneció fiel; en cuya consecuencia tuvo que secularizarse para ponerse a cubierto de la ruina que le amenazaba ${ }^{3}$. Yo me he preservado de ella en virtud de mi segregación del Cuerpo. Pero no deja de hacerme la guerra por medios indirectos. Si hubiese logrado la Definición General que el Rvdmo. Company me había 
ofrecido, y aun dado palabra al Sr. Campomanes de premiar así mis tales cuales méritos, podría yo estar con más serenidad por la seguridad con que en tal situación estaría de los insultos y artificiosas tramas de los buenos hermanos. Pero dicho Rvdmo. (que se halla por creación de Su Santidad Ministro General de la Orden) por contemplación del P. Salinas, Obispo de Tortosa y a los Moñinos, no tuvo valor de ejecutarlo, y más faltando el respeto de Campomanes a quien Floridablanca había hecho deponer del Gobierno del Consejo. Supuestos estos principios, cuya relación de hecho por escrito y de palabra al nuevo Ministro de Estado el Conde de Aranda (a quien de nuevo he presentado mi obra) no sé qué determinación se tomará acerca de ella y de mi persona. Desde luego no ha parecido bien que la Religión se haya portado con tanta indiferencia en no haberme dispensado la menor condecoración. Las Revoluciones del Ministerio con las consecuencias de la caída de Floridablanca, a quien se acaba de arrestar en un Castillo de Pamplona, es regular retarden el éxito de mis cosas, y yo temo que entretanto los enemigos que non dormiunt nisi mala fecerint, maquinen contra mí alguna diablura.

Estoy persuadido altamente del especial favor y afecto que siempre he debido a V. Excia. y que si estuviese en su mano, ya estaría libre de estos apuros y aflicciones que tanto han ejercitado mi paciencia. Las circunstancias de mi situación actual no permiten pueda disfrutar el favor de V. Excia. en la apreciable oferta que me hace. ¿Qué satisfacción sería la mía si lograse hacer a V. Excia. una visita! Pero para esto necesitaría de muchas licencias que probablemente no se me concederían. Dios ordene que alguna vez tenga yo este contento y esta dicha.

El Sr. Bayer hace cerca de dos meses que se retiró a Valencia. Está en guerra literaria con el erudito alemán Olao Gerardo Tychsen, que en una Disertación acaba de impugnar al Sr. Bayer probando la ilegitimidad de las monedas samaritanas y respondiendo a los nuevos argumentos que este señor emplea en sus Vindicias. No sé si estas contestaciones le dejarán tiempo para trabajar en la obra que hace años tiene ofrecida sobre las monedas de caracteres desconocidos ${ }^{4}$.

Casiri dejó casi concluida su apreciable obra de los Cánones arábigos. Pero no se trata de dar la última mano, ni menos de publicarla. Es lástima que bagatelas se lleven la primera atención.

Ruego a V. Excia. rinda mis respetos al Rvdmo. Sr. su amado hermano y Rvdmo. P. Fr. Vicente Salgado y a todos los demás señores de mi 
conocimiento y especial amistad. Dios guarde la importante vida de V. Excia. dilatados años.

B.l.m. a V. Excia. su muy fiel amigo, obligado y seguro servidor, Fr. José Banqueri

\section{NOTAS}

1 Cuidados Literarios do Prelado de Beja en graça do seu Bispado. Lisboa: Na Officina de Simäo Thaddeo Ferreira. Anno MDCCXCI. Con Licença da Real Meza da Comissäo Geral sobre o Exame e Censura dos Livros. Según Francisco da Gama Caeiro, Frei Manuel do Cenáculo: Aspectos da sua actuaçäo filosófica (Lisboa: Instituto de Alta Cultura, 1959), págs. 317-8, Cenáculo en esta obra es donde mejor manifiesta su inmensa erudición y su orientación filosófica; para Jacques Mercadé, no sólo encierra una erudición muy grande, sino que es a la vez una reflexión sobre el trabajo pastoral en el medio rural.

2 Ya hemos visto cómo Rafael había manifestado a Cenáculo en 1786 la «infidelidad y alevosía” de Sánchez, abandonando a sus antiguos favorecedores y pasándose al bando de los contrarios. El 9 de marzo de 1787 volvió a insistir Rafael ante Cenáculo sobre este cambio de Sánchez, calificándolo de «muy falso con nosotros, ingratísimo a los grandes beneficios que se le han hecho, y en fin un Judas traidor y aleve, y el mayor enemigo que tenemos hoy. Esto es preciso decirlo por inteligencia y gobierno de $\mathrm{V}$. Excia.; por lo demás le perdonamos cristianamente». B.P.E., CXXVIII/1-6, fols. 297v.-298v.; 301-302v. Autor de varias obras que pueden verse en Palau, el tratadito de la Religión a que se refiere Banqueri lleva por título Divina Christianae Religionis institutio et propagatio adversus hujus temporis libertinos. Madrid: Viuda de Pedro Marín, 1791.

3 Además de la ya referida carta de Jiménez a Cenáculo dándole la noticia del fallecimiento de Rafael, se conservan otras varias. B.P.E., CXXVII/2-13, fols. 66-70. En una que le envió en enero de 1790 , le comunica cómo pensaba presentarse a oposiciones para la cátedra de Retórica y Prosodia de la Universidad de Granada. Aparentemente ya entonces estaba secularizado.

4 La secuencia de los sucesos de esta «guerra literaria» fue la siguiente: Habiendo publicado Pérez Bayer su obra De Numis Hebraeo Samaritanis. Valentiae Edetanorum: Ex Officina Benedicti Monfort, 1781 , edición de la que dice Palau ser «una de las más nítidas de la oficina de los Monfort, tirada en papel de hilo, e ilustrada con retratos, vin̄etas, medallas y láminas abiertas en cobre», y por habérsela impugnado el alemán Oluf Gerhard Tychsen (1734-1815), Pérez Bayer respondió a la impugnación en sus Numorum Hebraeo-Samaritanorum vindiciae, Valentiae Edetanorum: Ex Officina Monfortiana, 1790. Nueva impugnación de Tychsen con De Numis hebraicis diatribe, qua simul ad... Franc. Perezii Bayerii objectiones respondetur. Rostochii: Typis Adlerianis, 1791, y nueva respuesta de Bayer publicando Legiti. midad de las monedas hebreo-samaritanas. Confutación de la diatriba De numis hebraicis de D. Olao Gerardo Tychsen, Consejero del Sr. Duque de Mecklembourg, Profesor de Lenguas orientales y primer Bibliotecario de la Universidad de Rostoch. Valencia: En la Oficina de D. Benito Monfort, 1793. 
Madrid 22 de Febrero de 1793

Excmo. Señor

Muy Señor mío y mi especial favorecedor: Recibí la apreciabilísima de V. Excia. con el atraso que sabe y habrá dicho nuestro Sousa; pues ella y los cuatro ejemplares de los Cuidados Literarios no llegaron a mis manos hasta mediados de enero. No he contestado antes a V. Excia. por esperar decirle que había ya entregado o dirigido los libros a las respectivas personas para quienes venían, y esperar la contestación de don Juan Bautista Muñoz, que la ha diferido algunos días por querer leer antes la eruditísima y preciosa obra de V. Excia. ${ }^{1}$.

El Sr. Bayer se halla en Valencia cerca de un año ha, y ya habrá recibido el libro y carta de V. Excia. por medio de don Manuel Monfort ${ }^{2}$, paisano suyo y Tesorero de esta Biblioteca Real, quien asimismo se encargó de dirigir al Sr. Mayáns su respectivo ejemplar y carta ${ }^{3}$.

Dicho Sr. Bayer está imprimiendo en Valencia segundas Vindicias contra el alemán Tychsen que volvió a impugnarle al descubierto. No me parece merecía el asunto tan pesadas contestaciones ni discusiones tan prolijas. Y es lástima que el Sr. Bayer se haya distraído en esto pudiendo y aun debiendo ocupar más útil y dignamente el tiempo en el tratado que tiene ofrecido sobre nuestras monedas antiguas fenicias y griegas desconocidas; lo que sin disputa sería de mayor interés a nuestra antigua literatura, y que aun de su primer tratado de las Medallas Hebreo-Samaritanas. Mucho recelo con Barthelemy que esta obra ha de quedar en mera promesa ${ }^{4}$; y más, cuando la edad del Sr. Bayer es bastante avanzada, aunque a la verdad no muy achacosa ${ }^{5}$.

Mi situación es la misma que dije a V. Excia. en mi última carta, y yo estimo infinito a V. Excia. los útiles y apreciables consejos que me da sobre prudencia, resignación y paciencia; los cuales ciertamente han sido muy oportunos y no han dejado de reanimar mi casi absoluto desaliento. Lo que hay de nuevo en el día es, que mi obra con el expediente ha pasado de la Secretaría de Estado a la de Gracia y Justicia con recomendación del Duque de Alcudia. Pero las circunstancias políticas presentes hacen que todo lo literato vaya con lentitud; y así no sé cuando se verificará el resultado que espero.

Quedo entendido en remitir a V. Excia. por medio de nuestro Sousa la 
continuación de la obra del Abate Andrés, esto es, el tomo cuarto y quinto en folio, pues hasta ahora no han venido más, y los tres tomos primeros de la traducción castellana, hecha por su hermano Don Carlos ${ }^{6}$. Hago varias diligencias para encontrar el continuador de Zurita, Argensola, que sólo falta a V. Excia., y aunque es algo raro no desconfío de que aparezca; en cuyo caso irá con los otros libros ${ }^{7}$.

Deseo que V. Excia. continúe con la más robusta salud, a pesar de los pocos gustos y satisfacciones que el mundo ingrato le ha of recido, lo que me tiene lleno de indignación. Pero paciencia.

Ruego a V. Excia. rinda mis respetos a su amado hermano nuestro Rvdmo. Sr. Soledade, y mande a su aftmo. y obligado servidor, que besa su mano,

\section{Fr. José Banqueri}

Excmo. Dr. Don Fr. Manuel del Cenáculo Vilas Boas.

\section{NOTAS}

1 Sobre la amistad y relaciones de Cenáculo con Muñoz, véase el extenso estudio del profesor León Bourdon, «Relations «Literaires» Portugaises de Juan Bautista Muñoz (17841799)», en Arquivos do Centro Cultural Português, VIII (1974), págs. 405-536.

2 Manuel Monfort era Tesorero de la Biblioteca Real, director de su imprenta y fundidor de letras desde el 23 de marzo de 1784, y Tesorero Jubilado desde abril de 1794 hasta su fallecimiento en febrero de 1806.

3 No se refiere al insigne don Gregorio Mayáns y Siscar (1699-1781), con el cual Cenáculo mantuvo una interesantísima correspondencia, acerca de la cual tiene prometido un estudio la profesora francesa Marie-Hélène Piwnik, sino a su hermano el presbítero don Juan Antonio. Cenáculo había conocido a ambos hermanos con motivo de su viaje a Valencia en 1768.

4 Juan Jacobo Barthelemy (1716-1795), arqueólogo y numismático francés. Estudió la carrera eclesiástica, y si bien no llegó a ordenarse, conservó su estado clerical. Autor de varias obras, fue conservador del Gabinet des Médailles de la Biblioteca Nacional de París.

5 Pérez Bayer fallecería poco después, el 27 de enero de 1794. El 25 de octubre de 1783 había sucedido a don Juan de Santander al frente de la Real Biblioteca.

6 El abate Juan Andrés (1740-1817), jesuita expulso muy conocido por su obra Dell'ori. gine, progressi, e stato attuale d'ogni letteratura. Parma: Dalla Stamperia Reale, 1782.1798. 7 vols., que traducida al castellano por su hermano Carlos Andrés, fue impresa en diez volúmenes por Antonio Sancha entre los años 1784-1806.

7 Bartolomé Leonardo de Argensola (1562-1631) escribió una Primera Parte de los Anales de Aragón que prosigue los del Secretario Gerónimo Zuritu desde el año MDXVI. Zaragoza: Juan de Lanaja, 1630. 
Madrid 22 de Noviembre de 1793

Excmo. Señor Obispo de Beja

Muy Señor mío de todos mis afectos y veneración: He diferido la contestación a la muy apreciable de V. Excia. hasta poderle decir que había encontrado el Argensola y el Bulario de la Orden de Santiago ${ }^{1}$; cuyos libros y los demás encargados qued an ya en casa del Embajador de Portugal en un cajoncito rotulado para nuestro Sousa, que llevará Carreño en el primer viaje que hará a fines de este mes. No fueron en el último que hizo por querer yo que fuesen juntamente los dos citados libros, que aún no había tenido entonces la felicidad de encontrar. También va un ejemplar que regala a V. Excia. Don Juan Bautista Muñoz del primer tomo de su Historia del Nuevo Mundo².

He preguntado sobre el Mariana de la edición de Valencia, y me dicen, que por la subscripción se entregan solamente los seis tomos en papel; que para los demás, hasta la conclusión, no se suscribe, sino que se venderán según sus respectivos costos. En esta atención me dirá V. Excia. qué tomos de los seis le faltan, y quien tiene la suscripción para que en vista de ella me los entreguen; y entonces compraré el séptimo que ya se ha publicado, y acaso el octavo que no tardará en publicarse ${ }^{3}$.

He leído con mucho gusto y edificación la docta Pastoral que el fervoroso celo de V. Excia. dirige a sus Diocesanos. ¡Ojalá fuese leída de todos los fieles! En ella ataca V. Excia. enérgicamente a los falsos filósofos de nuestros infelices tiempos en sus mismas trincheras después de hacer un retrato muy vivo de ellos y de su pretensa filosofía. Su furor y vanidad no les permite abrir los ojos a la brillante luz para conocer la inconexión y debilidad de sus discursos, su locura y extravío, y la eterna perdición que les aguarda. ¡Oh, y cuánto cunde por todas partes esta generación impía! También abunda por aquí semejante canalla. Dios por su misericordia contenga esta irrupción de naturalistas y libertinos, que por medio de sus diabólicas máximas se lisonjean reformar el mundo; y suscite en su Iglesia muchos Pastores de la instrucción, celo y vigilancia de los que se oponen con vigor apostólico a este torrente de errores y libertinaje ${ }^{4}$.

Mucho he celebrado que la muestra de la impresión de mi obra haya merecido la aprobación de V. Excia. Me es muy molesta y penosa la corrección por no tener auxiliar competente para los cotejos que es necesario hacer con los respectivos originales ${ }^{5}$. 
Hasta ahora no he encontrado cosa respectiva a Beja. Pero citándose en esta obra varios autores de la Península, quizá en lo que resta por interpretar de la segunda parte hará mención el Mahometano de Sevilla de algún escritor de Re Rustica o de veterinaria que fuese natural de esos países. En el capítulo décimo de la primera parte de las máximas que extractó de otra obra grande intitulada Agricultura Nabathea sienten y prueban bien en la parte Occidental de España, que es lo que significa aquel nombre arábigo ${ }^{6}$.

El celo de V. Excia. le hace desear la publicación de la Colección de los Cánones que dejó interpretados el docto Casiri. Pero parece que no es esto de esperar en la era presente, que por otra parte parecería la más oportuna. La impresión de la Agricultura ha sido especie de triunfo, y a no haberme remitido la obra a la censura del Conde de Campomanes, celoso promovedor de este género de literatura, ciertamente hubiera padecido naufragio. Espero que dicho Señor me dé copia del dictamen que dio, para remitirla a V. Excia. de quien él es muy afecto ${ }^{7}$.

Dirigí a mi condiscípulo el P. Salas la inclusa de V. Excia. y me contesta en esa, que igualmente incluyo para que V. Excia. vea el estado de sus trabajos; y que no es el Cronista de la Provincia, como merecería serlo, sino el bueno de Fr. Domingo de Herrera, de quien parece es sólo auxiliar.

Dis me conserve la preciosa vida de V. Excia. muchos años.

B.l.m. a V. Excia. su afmo. y muy obligado servidor,

$$
\text { Fr. José Banqueri }
$$

P.D.

El Rey Católico ha elegido por Confesor al Rudmo. P. Comisario de Indias de la Provincia de Extremadura. Si acaso era conocido de V. Excia. y por esta razón le escribe la enhorabuena, le ruego le diga una palabra de recomendación, lo cual perfeccionará el afecto que me tiene mostrado ${ }^{8}$.

\section{NOTAS}

1 Bullarium aecuestris Ordinis S. Jacobi de Spatha. Madrid: Ioannes de Aritzia, 1719.

2 Historia del Nuevo Mundo. Escribíala D. Juan Baut. Muñoz. Tomo I. Madrid, Por la Viuda de Ibarra, MDCCXCIII.

3 Historia General de España que escribió el P. Juan de Mariana. Ilustrada en esta nueva impresión de tablas cronológicas, notas y observaciones críticas con la vida del autor. Con Superior permiso. En Valencia y Oficina de Benito Monfort, 1783.1796.

4 Si bien Cenáculo imprimió en 1793 algunas Instrucciones Pastorales en las que trata de 
la situación política y filosófica contemporánea y que podían dar pie a reflexiones como las que hace Banqueri, es probable que aquí éste se refiera a la Saudacçáo pastoral do Excmo. e Rmo. Bispo de Beja no fim da sua Visita Geral, em o anno de 1788, impresa en Lisboa en este mismo año de 1793. Según Mercadé, ob. cit., pág. 512, en este escrito no sólo of rece Cenáculo un balance de su diócesis, sino también las exigencias de una nueva fe, una meditación sobre las corrientes filosóficas de la época.

5 Evidentemente, ya se habían comenzado a imprimir los primeros pliegos del Libro de Agricultura y Banqueri había enviado a Cenáculo una muestra de los mismos. El mismo envío hizo Banqueri a su condiscípulo residente en el convento de Alcalá la Real Fr. Pedro de Salas, el cual a su vez expresaba sus impresiones en los siguientes términos: "Celebro mucho que se haya comenzado ya a imprimir tu Primera Parte por orden del Rey y a cuenta de la Real Biblioteca, y que sea en una impresión tan limpia y de tan buena letra. De las hojas que me remites infiero las grandes tareas que te habrá costado la versión. Me agrada la pureza del estilo castellano, las notas, adiciones y exposiciones en los puntos difíciles. Y me hago cargo del mucho trabajo que ahora se te junta en instruir a los impresores en los primeros elementos del Arabe, para que puedan formar las palabras y unos nombres tan difíciles de escribir aun en nuestro idioma. Dios te dé fuerzas para concluir toda la obra, y otras, y ceda en honor de Dios, de la Nación y de la Orden".

Sobre Fr. Pedro de Salas y la naturaleza de sus relaciones con Cenáculo, a las cuales se refiere Banqueri al final de esta carta, puede verse nuestro artículo, «Proyecto español de una Historia General de la Tercera Orden Regular de San Francisco (S. XVIII)», en Archivo Ibero-Americano, XL (1980), págs. 37-72.

- La Agricultura Nabathea recibe este nombre por habérsele atribuido su autoría a los nabateos. Descubierta la falsedad de tal atribución, se ha demostrado que se trata de una «compilación típicamente árabe, sobre originales griegos adulterados con mucha imaginación. La importancia de esta fuente para Ibn el Awwam se puede apreciar por el hecho de que Ibn Jaldum, al mencionar la obra del agricultor sevillano, la juzgó un resumen de la Agricultura Nabatea, a la que aquél cita unas trescientas veces». Conf. César E. Dubler, "Posibles fuentes árabes de Gabriel Alonso de Herrera», Al-Andalus, VI (194l), pág. 136.

7 Entre la correspondencia dirigida a Cenáculo que se conserva en la Biblioteca Pública de Evora se encuentran dos cartas de Campomanes. Cod. CXXVII/2-13, núms. 4496-4497.

8 Lo era Fr. Juan de Moya, hijo de la Provincia de San Miguel. Fue nombrado Comisario el 20 de enero de 1793 y el 13 de abril del siguiente año fue nombrado arzobispo titular de Farsalia.

Madrid 8 de Agosto de 1794

Excmo. y Rvdmo. Sr. Obispo de Beja

Mi muy amado y venerado Padre Señor: Recibí la muy apreciable de V. Excia. celebrando la buena salud que goza a pesar de una vida tan trabajada como la que V. Excia. ha tenido y tiene, y a que su activo celo siempre le estimula emprendiendo nuevas tareas, sin permitirse pausa ni descanso. 
Dios quiera, que con la expedición a la Plaza de Sines ${ }^{1}$ logre el fin de robustecer y vigorizar $V$. Excia. su importante salud; aunque para esto sería conveniente no llevar allá proyectos de nuevos trabajos.

Hace pocos días recibí las Memorias Históricas ${ }^{2}$, Admonitio ad Fra. tres $^{3}$, y la Instrucción Pastoral; tres ejemplares de cada cosa. Al Sr. Muñoz entregué los respectivos, y es regular conteste desde Valencia, a donde la necesidad de reparar su indispuesta salud le ha obligado a retirarse por algún tiempo. A mi condiscípulo el $\mathrm{P}$. Salas remitiré los suyos en la primera oportunidad.

A pesar de las tareas actuales, que me son bien penosas, he comenzado a leer estas preciosas producciones de $\mathrm{V}$. Excia. en que no menos brilla su celo y piedad, que su gusto y vasta erudición. Dios por su bondad prolongue a V. Excia. tan preciosa vida para bien de sus diocesanos y de otros, y para mayor honor y ornamento de nuestra Orden Tercera. ¿Qué fines tan gloriosos se propone V. Excia. en todo cuanto hace! ¡Oh, alma grande y noble!

¡Señor!, y ¡cómo corresponderé yo a los nuevos efectos con que me favorece la beneficencia y generosidad de V. Excia. después de tantos beneficios recibidos! Señor Dios sea la recompensa. Gracias; y V. Excia. reciba en recambio a tanto favor un corazón penetrado de un puro amor y de un humilde reconocimiento. Asimismo tengo la satisfacción de ofrecer a $\mathrm{V}$. Excia. los nuevos auxilios que he debido a la piedad del Rey en una Prestamérita en el Obispado de Córdoba, que me ha conferido Su Magestad y que (según dicen) ascenderá su renta a 400 ducados anuales; con lo cual ya mi situación no será tan dura como hasta aquí lo ha sido ${ }^{4}$.

Yo no sé si los libritos que V. Excia. me encargaba con los Guías de Forasteros y del Estado Eclesiástico son los que con estos dirigí a nuestro Sousa por medio del Capellán del Sr. Embajador. Me he quedado con esta duda por no haber entendido bien una sola expresión de la carta. Si no lo fuera, se servirá V. Excia., o dicho Padre Sousa, de repetirlo como también de no tener ociosa mi obediencia en lo demás que insinúa V. Excia. tiene que encargarme y en cuanto sea de su agrado.

Según me dijo Muñoz vive aún Don Juan Antonio Mayáns, y el mismo Muñoz fue con el encargo de saber si recibió los Cuidados Literarios.

Viva V. Excia. los largos años de mi deseo, como se lo ruego a su Divina Magestad en mis cortas oraciones y en el sacrosanto sacrificio. 
Excmo. Señor, B.l.m. a V. Excia. su más afecto, rendido y obligado servidor,

\author{
Fr. José Banqueri
}

\title{
NOTAS
}

1 Villa costera en el término de la diócesis de Beja a la cual Cenáculo solía trasladarse para descansar.

2 Memorias Históricas, e Appendix Segundo a Disposiçäo Quarta da Collecçăo das Disposiçöes do Superior Provincial, para a Observancia, e Estudos da Congregaçāo da Ordem Terceira de S. Francisco. Tomo II. Lisboa, Na Regia Officina Typografica. Anno M.DCC.XCIV. Con licença da Real Meza da Comissäo Geral sobre o Exame, e Censura dos Livros. Aunque editada tardíamente, esta obra ya estaba concluida en 1773 y es continuación de un primer volumen publicado bajo el título de Disposiçōes do Superior Provincial para a Observancia Regular, e Litteraria da Congregação da Ordem Terceira de S. Francisco destes Reinos, feitas em os annos de mil sessenta e nove a setenta. Tomo Primeiro. Lisboa, Na Regia Officina Typografica. Anno M.DCC.LXXVI. Con licença da Real Meza da Comissão Geral sobre o Exame, e Censura dos Livros. Este primer volumen, como se desprende de su mismo título, es una recopilación de las disposiciones dictadas por Cenáculo durante los años de 1769 y 1770 , orientadas a promover la reforma de su Provincia, tanto en el aspecto disciplinar como en el intelectual. La cuarta de las disposiciones de esta recopilación termina con la inclusión de un apéndice, que ilustra con numerosas noticias la reforma de las ciencias y de las artes en Europa, escrito con la intención de que ejemplo tal sirviese de estímulo a sus religiosos para que también entre ellos se propagase el buen gusto en el saber. Las Memorias Históricas no son sino una continuación de dicho apéndice, si bien restringiéndose a jlustrar en ellas la historia literaria de la Tercera Orden Regular en Portugal y sus dominios, desde los primeros tiempos de la Orden hasta ya mediado el siglo XVIII; amplísima recopilación de datos enriquecida por Cenáculo con valiosísimos comentarios y buen número de documentos.

3 De repetendis fontibus doctrinae, Moderatoris Provincialis Tertii Ordinis Sancti Fran. cisci per Lusitaniam, admonitio ad sodales, quum Praefecturam deponeret. Anno 1770. Innocencio da Silva, Dicciónario bibliografico português (22 vols.; Lisboa, 1858-1914), V, págs. 301-302, dice que esta Patente, que abarca 55 páginas en folio, sin indicación de lugar ni año, es la versión latina de la impresión portuguesa de una Patente sobre o verdadeiro systema de theologia, que se deve seguir na provincia da Ordem Terceira de Penitencia, segundo o saudavel determinação do SS. Padre Clemente XIV, impresa por Simāo Thaddeo Ferreira en 1793, y que ambas estaban destinadas a formar el tomo III de las Disposiçöes do Superior Provincial.

421 de Abril de 1794

El Rey se ha servido conceder al P. Fray Josef Banqueri la Prestamera de la Mitación de Patomarejos, en el Obispado de Córdoba, con calidad de que permanezca agregado a la Real Biblioteca con el sueldo, o ayuda de costa que por ella se le da, y de continuar la traducción e impresión de la obra de Agricultura de Abu-Zacaría Ebn el-Awam, y las demás que se Le encarguen relativas a la literatura arábiga. Lo que participo a V.S. de orden de S.M. para 
su inteligencia y cumplimiento. Dios guarde a V.S. muchos años. Aranjuez 25 de Abril de 1794.

Eugenio de Llaguno

Sr. Don Pedro Luis Blanco.

Madrid, Biblioteca Nacional. Papeles Secretaría. Expedientes Personales, José Banqueri.

\section{VI}

Madrid 30 de Octubre de 1795

Excmo. Señor Obispo de Beja, Don Fr. Manuel del Cenáculo

Muy Señor mío y más venerado Padre y Señor: He recibido la muy apreciable carta de V. Excia. de 1 de octubre, inclusa en la del P. Sousa, y celebro en mi corazón, que a pesar de la edad avanzada y continuos trabajos en que infatigablemente se ejercita el activo celo de V. Excia., se mantenga con la salud y robustez posible, en lo que tantos y tanto debemos interesarnos y yo muy especialmente.

La noticia dada por Don Ayres Tinoco es cierta; y ya yo había encargado al P. Sousa la comunicase a V. Excia. hasta que hechas las diligencias del pase del Breve de mi secularización, y efectuada ésta, lo hiciese yo con la extensión correspondiente, refiriendo a V. Excia. la historia de toda esta novedad. El origen, pues, de ella ha sido propiamente la indiferencia con que por la sola razón de religioso he sido siempre considerado por los compañeros y jefes de la Real Biblioteca; en la cual no habiendo por esta causa logrado ni un grado de ascenso desde el año de 1784, creí que mi honor y el de mi hábito exigía que yo pidiese mi retiro, a lo menos por indirectas insinuaciones; y más cuando la consignación de los 500 ducados anuales no era suficiente, no digo para la subsistencia literaria, mas ni aún para la física en unos tiempos como los presentes. Indicando esto al Ministerio, y no habiendo Plaza vacante de Bibliotecario, o que no pudiera ascender, se me contestó, que siendo la causa de este atraso el no haber querido yo secularizarme (cosa, que aun viviendo los PP. Mohedanos se me indicó más de una vez, y a que siempre resistí) era necesario hacerlo ahora para poderme dar alguna pensión que fuese equivalente del ascenso obtenido. A lo cual contesté, que para esto no era necesaria la secularización puesto que mi regla me dejaba habilitado obtener semejante renta y aun beneficios simples, excepto los Capitulares. Pero insistiendo en que debía secularizarme, y por otra parte considerando yo el trastorno de la Provincia y que si volvía a ella sería ciertamente sacrificado a imitación de los Padres, di mi consentimiento para la secularización, mas con la condición precisa 
que mi tránsito había de ef ectuarse con honor, pidiéndose al mismo tiempo la Gracia de quedar habilitado para obtener Prebendas. En efecto, pidióse a Su Santidad la doble gracia por la Secretaría de Estado a nombre de Su Magestad; y ya obtenida, se me proveyó en una corta Prestamera para que con su renta me secularizase. Yo lo resistí, representando al Ministro, que no era esto lo tratado; en cuya atención se dignó la piedad del Rey por influjo del Señor Don Eugenio Llaguno y Amírola (nuevo Ministro de Gracia y Justicia y antiguo favorecedor mío proveerme en una Media Ración de la Iglesia de Murcia, que ofrezco a la disposición de V. Excia. aunque no deba tomar posesión de ella hasta cumplido el año de la vacante, que será por enero del año próximo ${ }^{1}$. Hace pocos días que se efectuó mi tránsito al Clero secular, el cual siendo en los términos expresados, ha sido de la aprobación del General de la Orden, y del Iltmo. Arzobispo de Farsalia Don Juan de Moya, Confesor del Rey, a quienes consulté sobre el particular. Se ha pedido por el Ministerio la dispensa de residir, que según el tenor y el espíritu del Breve parece ser consecuencia necesaria su concesión; pues de otra suerte no podría yo continuar los trabajos literarios en que estoy entendiendo, y mucho menos de cuidar de su prolija impresión. En el día está concluida la de la primera parte de la Agricultura en un tomo de 174 pliegos, el cual no se publicará hasta la conclusión de la segunda y última, cuya impresión no podrá comenzar hasta la primavera.

Lleva Carreño en este viaje los primeros libros encargados. Los de la lista que me incluye V. Excia. y los demás que me avisa se irán buscando y juntando en los términos que la moderación y prudencia de V. Excia. me previene, esto es, en los ratos de ocio. Ya dije al P. Sousa que para la remesa del dinero es buen conducto el R. P. Custodio Capellán del Sr. Embajador. Debo prevenir a V. Excia. que no es de la historia latina de Mariana de la que habla la Gazeta n. ${ }^{\circ} 57$, si no de una edición nueva castellana que en tomos pequeños ha hecho el impresor Cano ${ }^{2}$. Así, espero nuevo aviso para si ésta se ha de comprar o no, con las advertencias de Mondéjar.

La librería del difunto amigo el Sr. Velasco no se vende suelta, sino entera; y hasta ahora no ha salido comprador alguno. Su tasación asciende a cerca de trescientos mil reales. No hay índice de ella impreso, ni piensa imprimirlo por ahora, el cual contiene dos tomos en folios o más ${ }^{3}$.

Don Juan Bautista Muñoz apreció mucho la fina memoria de V. Excia. a quien dijo escribiría en la primera oportunidad. Ya está restablecido de 
sus indisposiciones y es regular que no tarde mucho en imprimir el tomo segundo de su obra.

Va en el cajoncito la Ilustración de la inscripción hebraica de Toledo. Ahora se pretende por algunos que la copia que supone Heydeck haber sacado de ella es supuesta por haberse cubierto la pared donde se contiene de yeso muchos años ha, y poco después que Bayer la copió; la cual entonces no se hallaba íntegramente conservada, como ahora pretende dicho Heydeck. En la cosa hay partidos, y empeños personales, y aún no se sabe qué resultará de esta contienda principiada, en que por una y otra parte se quiere tome partido la Academia de la Historia, que primero aprobó la obra de Heydeck ${ }^{4}$.

Ruego a V. Excia. me ofrezca a la disposición de su amado hermano y Señor mío, y que ambos no tengan ocioso mi afecto y obligación, comunicándome sus preceptos. Dios me guarde la importante vida de V. Excia. los años de mi deseo.

Excmo. Señor, B.l.m. a V. Excia. su aftmo. amigo y venerador, y obligadísimo servidor y capellán,

\section{José Banqueri}

\section{ANEXO}

Importe y razón de los libros que lleva Carreño para el Excmo. Sr. Obispo

\begin{tabular}{|c|c|c|c|}
\hline & & & $\begin{array}{l}\text { Precio } \\
\text { en } \\
\text { Reales }\end{array}$ \\
\hline Diccionario del P. Larramendi ${ }^{5}$ & 2 & $4 .^{\circ}$ & 400 \\
\hline Indice de los Libros Prohibidos ${ }^{6}$ & 1 & $4 .^{\circ}$ & 23 \\
\hline Dos Guías de Forasteros y Eclesiástica ${ }^{7}$ & & & 20 \\
\hline Ilustración de la inscripción hebrea de Toledo & & & 9 \\
\hline Aforismos de Hipócrates inéditos ${ }^{\theta}$ & & & 6 \\
\hline \multirow[t]{2}{*}{ Frete a Carreño } & & & 33 \\
\hline & & & 491 \\
\hline
\end{tabular}

\section{NOTAS}

1 Sobre Llaguno puede leerse el artículo de Ricardo de Apraiz, «El ilustre alavés D. Eugenio de Llaguno y Amirola. Su vida, su obra, sus relaciones con la Real Academia de la Historia y con la Real Sociedad Vascongada de los Amigos del País», en el Boletín de la Real 
Sociedad Vascongada de los Amigos del País, IV (1948), págs. 53-95. Desempeñó el cargo de Ministro de Gracia y Justicia durante los años 1794-1796.

2 La noticia dada en la Gaceta de Madrid el 17 de julio de 1795, se expresaba en los siguientes términos: «Juicio de la Historia de España del P. Juan de Mariana, continuando en 204 advertencias, por D. Gaspar Ibáñez de Segovia, Marqués de Mondéjar. Aunque el $P$. Mariana es de los escritores [...] los publicó con una prefación muy erudita, de orden y a expensas de la Academia Valenciana Mayáns, en folio, el año de 1746. Para que ahora sirvan de continuación a la Historia del P. Mariana, cuya edición en $80^{\circ}$ acaba de merecer la general aceptación, se reimprimen con el discurso preliminar del Sr. Mayáns, las citas de los libros y capítulos a donde corresponden, y un copioso indice de las personas, cosas y palabras más notables que contienen. Será un tomo en $88^{\circ}$ marquilla, de letra igual a la del segundo prólogo del tomo $1 .^{\circ}$ de la citada edición». La impresión de Cano, realizada entre los años 1794-1795, comprende diez volúmenes.

3 El «difunto amigo el Sr. Velasco» no es otro que don Fernando José de Velasco Ceballos, el cual había sido Presidente de la Cancillería de Granada desde 1766 hasta 1770, de donde pasó a Madrid como miembro del Consejo Real, de la Suprema Inquịsición y asesor del Consejo Supremo de Guerra. Cenáculo lo había conocido en Granada en 1768 a su paso por aquella ciudad camino de Lisboa, debido a la amistad que lo unía con los Mobedano, de quienes era favorecedor y con quienes participaba su amor por los libros. En la Biblioteca Pública de Evora se conservan algunas cartas de Velasco a Cenáculo, Cod. CXXVII/1_8, fols. 137-162v.

Testimonio elocuente de las inquietudes literarias de Velasco y de su amor a los libros y manuscritos, fue el gran número de los que dejó a su muerte, como consta del índice a que se refjere Banqueri, y que hoy se conserva todavía manuscrito en la Biblioteca Nacional de Madrid, Mss. 3602-3603. En el segundo volumen de dicho índice, al final, aparece escrita la siguiente tasación efectuada por el librero Antonio Baylo: «Digo yo el abajo firmado que he visto, reconocido y tasado los libros contenidos en este Catálogo 2 tomos en folio que fueron del Iltmo. Sr. D. Fernando de Velasco del Consejo y Cámara de S.M. A los cuales he dado el valor, según su respectivo estado y saber y entender. Madrid 3 de junio de 1791.

Reconocida y examinada de nuevo por los Sres. Interesados la suma de los libros tasados en estos 2 tornos, parece se advirtió que habia la equivocación de 1.388 reales vellón puestos de menos: los cuales añadidos a los 321.563 reales que se sacan arriba importa y asciende (no habiendo equivocación de suma u otra alguna) a 322.951 reales vellón. Y se advierte que si se separan de estos thos tomos varios libros que hay en ellos anteriores al año 1500 para pasarlos al Catálogo de Libros del Siglo $1 .^{\circ}$ de la Imprenta, el importe de ellos según su tasación será de menos valor y se rebajará de la total suma de estos cuadernos. Lo que prevengo para que no se aplique su valor en dos partes en perjuicio de alguno. En cuya conformidad to firmo en Madrid a 4 de octubre de 1791. Antonio Baylow.

4 Heydeck, ex-rabino converso, acababa de publicar con aprobación de la Real Academia de la Historia un estudio acerca de una inscripción hebraica del siglo XIV, conmemorativa de la fundación de la sinagoga toledana, que más tarde sería convertida en la famosa iglesia de Ntra. Sra. del Tránsito. Dicho estudio lleva por título Ilustración de la inscripción hebrea que se halla en la iglesia del Tránsito de la ciudad de Toledo, por don Juan Joseph Heydeck. Con un apéndice a la ilustración de la inscripción hebrea de la Iglesia del Tránsito de Toledo, escrito para desengaño del público. Madrid: Imprenta Real, 1795. Alguien se dio cuenta de que el texto transcrito por Heydeck difería de otra transcripción del mismo texto efectuada por Pérez Bayer en 1752, según constaba en una memoria suya que permanecía inédita. La Academia de la Historia, que había aprobado la obra de Heydeck, nombró con este motivo una comisión formada por el P. Traggia, el dibujante Marina y Banqueri, los cuales se desplazaron 
a Toledo. El P. Traggia redactó un Diario de las operaciones para el reconocimiento y copia de la inscripción Ebrea de la Iglesia de Nuestra Señora del Tránsito en la ciudad de Toledo. Los hallazgos de esta comisión fueron publicados en el tomo III de las Memorias de la Real Academia de la Historia, págs. 31-70, con el título de Memoria de la Real Academia de la Historia sobre la Inscripción hebrea de la Iglesia de Nuestra Señora del Tránsito de Toledo, que con el título de Ilustración publicó Don Juan Joséf Heydeck el año de 1795. Los hallazgos de la comisión, favorables a Pérez Bayer, dejaron al descubierto que Heydeck nunca había visto dicha inscripción, si no que se había limitado a traducir al hebreo una versión española de dicha inscripción, tal como ésta aparecía en una crónica de las Ordenes de Caballería publicada por Francisco de Rades y Andrade en 1572, y que para restablecer algunas partes ya desaparecidas del texto se había valido del que también había publicado un judio en una obra impresa en Amsterdan en 1740 con el título Vas Transmigrationis. Conf. Nuno Daupias D'Alcochete, Humanismo e Diplomacia. Correspondencia Literaria (1789-1814) de Francisco José María de Brito com Dom Frei Manuel do Cenáculo (Paris: Centro Cultural Português, 1976), págs. 42-43.

Con motivo de la publicación del informe presentado por la comisión ya referida, la Real Academia de la Historia dejó afirmado lo siguiente: «Esta Memoria es la única que se debe mirar, entre las que se publican, como obra propia de la Academia, porque en ella trabajaron sus individuos, unos con sus desvelos, otros con sus luces, otros con sus consejos, y todos la adoptaron con su aprobación: por consiguiente se constituye tan responsable de lo que opina y afirma, como interesada en desengañar al público, y sostener la verdad. " MEMORIAS DE LA REAL Academia de la Historia, Vol. III, pág. (6).

5 Manuel de Larramendi, S. J., Diccionario trilingïe del castellano, bascuence, y latín. San Sebastián: Bartolomé Riesgo y Montero, 174.5 .

6 Indice último de los libros prohibidos y mandados expurgar para todos los Reynos y Señorios del Católico Rey de las Españas el Señor Don Carlos IV. Contiene en resumen todos los Libros puestos en el índice expurgatorio del año 1747, y en los Edictos posteriores hasta fin de diciembre de 1789. Madrid: Imprenta de Don Antonio de Sancha, 1790.

7 Según señala Palau, la Guía del Estado Eclesiástico seglar y regular de España se publicó desde el año 1795 al de 1862. Y añade: «Estos tomitos tienen poco valor comercial. Solamente alcanzan aprecio cuando se presentan revestidos de buenas encuadernaciones.» Respecto de la Guía de Forasteros, cree que la más antigua es la que se comenzó a imprimir en Madrid a partir de 1735 , pero añade que no está muy seguro de ello.

* Es probable que se trate de los Aforismos, traducidos al francés según el cotejo de veintidós manuscritos y de los intérpretes orientales, por el Sr. Lefebure de Villebrune. Trad. al castellano por un profesor de medicina. Madrid: Blas Román, 1794.

\section{VII}

Madrid 25 de Agosto de 1797

Excmo. Señor Obispo de Beja

Mi muy venerado y estimado Señor y favorecedor: Llegó ya el tiempo de remitir a V. Excia. los libros que hace año y medio me encargó fuese comprando sin fatiga, y que mis ocupaciones con algunas indisposiciones que 
he padecido en este mismo tiempo no me han permitido buscar con la prontitud que deseaba. Van todos los encargados por V. Excia. a excepción de algún otro, que no he podido encontrar. La Biblioteca en octavo con el texto latino y la traducción castellana no era venal; pero he conseguido que un subscriptor me traspasase la subscripción que tenía hecha para sí, y quedan satisfechos dos tomos más de los que van ahora, que son los que se pagan adelantados, cuando se recogen los dos últimos que salen de la prensa. De todos los libros va la lista con sus precios para no desagradar a V. Excia.; menos de los dos primeros tomos que regala a V. Excia. nuestra Academia de la Historia de las Memorias que va publicando, la Memoria contra Heydeck que por comisión de la misma extendí yo sobre la inscripción hebrea de Toledo, y un ejemplar que remite a V. Excia. nuestro co-Académico Don Juan Bautista Muñoz de su Elogio de Antonio de Lebrija.

Por no multiplicar cartas a V. Excia. (que considero siempre tan útilmente ocupado), esperaba esta ocasión de la remesa de los libros para congratularle y mostrarle la gratísima satisfacción que tuve en la asociación de V. Excia. a esta Academia y en la lectura que hizo el Secretario de ella de la Oración Gratulatoria y laudatoria que le dirigió V. Excia. y que fue de todos los individuos justamente aplaudida, congratulándose todo el cuerpo de la apreciabilísima adquisición que había logrado de una persona tan erudita y sabia, como lo es notoria y generalmente V. Excia.

Ya había participado a V. Excia. que el Excmo. Sr. Conde de Campomanes fue (después del difunto Casiri) el segundo censor de la obra de Agricultura, cuyo dictamen deseoso yo de que lo viese V. Excia. me ha franqueado dicho Sr. Conde, sólo para este fin, y así le incluyo una copia de él y de la carta suya al Ministro con que acompañaba dicho dictamen ${ }^{1}$.

La segunda y última parte de la traducción espero estará concluida a fines del próximo octubre; y luego que se haga la copia en limpio pasará al mismo ilustre Censor, y aprobada que sea, se procederá inmediatamente a su impresión, en la cual se consumirá cerca de un año y medio, que fue el tiempo que se empleó en la de la primera parte.

Ruego a V. Excia. rinda mis afectuosos respetos al Rudmo. Sr. Padre su amado hermano, a quien como a V. Excia. deseo siempre complacer en cuanto manden.

Dios me guarde la importante y preciosa vida de V. Excia. los dilatados y felices años que deseo. 
Excmo. Señor, B.l.m. a V. Excia. su afmo. amigo, rendido y obligado servidor,

\section{José Banqueri}

Excmo. Sr. Obispo de Beja, Don Fr. Manuel del Cenáculo

\section{NOTA}

1 Este dictamen de Campomanes y su carta al Ministro fueron publicados en el Catálogo da correspondencia dirigida a Fr. Manuel do Cenáculo Vilas Boas, Vol. IV, pp. 215-221.

\section{VIII}

Madrid 11 de Abril de 1798

Excmo. Señor Obispo de Beja

Muy Señor mío de todo mi mayor filial afecto: La necesidad que tuve de pasar y detenerme en el sitio de Aranjuez por unos días, y el esperar después que Carreño condujese los últimos libros encargados por V. Excia. me han obligado a diferir la contestación a las dos últimas apreciabilísimas de V. Excia. pues me había propuesto que dicho Carreño condujese igualmente todas las contestaciones del Sr. Director y Secretario de nuestra Academia, y del amigo Muñoz. Pero no habiendo podido yo recoger antes todos los libros y tardando el Carreño en hacer su viaje, no quiero diferir más mi respuesta, como lo ejecuto ahora contestando a todos los puntos que toca V. Excia. en sus dos últimas cartas.

Nuestra Academia agradeció sobremanera el regalo que por mi mano le hizo V. Excia. de algunos Códices preciosos y ya contesta el Secretario indicando el juicio crítico de una Junta que señaló el Director para reconocerlos y colocarlos con esta nota en el lugar que deben ocupar en la Biblioteca de la Academia ${ }^{1}$.

Con la elección de los nuevos Números los Sres. Saavedra y Jovellanos, ambos de nuestra Academia y verdaderamente sabios, esperan los amantes de la buena literatura, que ésta hará ahora mayores progresos por el fomento que la den, promoviendo y premiando a los literatos. Aunque yo esté muy distante de merecer este título han hecho la demostración (por el informe que se conserva en la Secretaría de Gracia y Justicia, y que dio de la primera parte de mi obra el Excmo. Sr. Conde de Campomanes) de promoverme a la Dignidad de Prior Claustral de la Catedral de Tortosa, que 
tengo la satisfacción de ofrecer a V. Excia. Aunque la renta de esta pieza eclesiástica no exceda mucho a la de la Prebenda que obtenía en la Catedral de Cartagena de Murcia, siempre es muy lisongero y honorífico el ascenso de Medio Racionero a Dignidad que con el tiempo me podrá proporcionar otro más ventajoso.

Leí al Sr. Conde de Campomanes las expresiones de las dos cartas de V. Excia. y yo no puedo ponderar la gratísima impresión que hicieron en su corazón, y el entusiasmo que con este motivo mostró en el justo y meritísimo elogio que hizo de la vasta y amena literatura de V. Excia., de su ardiente celo por los progresos de la sólida literatura, y de sus singulares prendas de corazón; de manera que aunque yo debía estar como lo estoy, más instruido en todo esto que dicho Excmo.; con todo, el modo con que Su Excia. me explicaba, me estremeció y me hizo derramar dulces lágrimas de puro contento. Me encargó mucho ponderar a V. Excia. su respeto y cordialísimo amor a su persona, y la gran satisfacción que tendría en disfrutar y participar de sus grandes luces e instrucción y de su amabilísima presencia. Añadió que yo dijese a V. Excia. le compadeciese en su ancianidad, cuyos naturales achaques le tienen imposibilitado de manejar libros, y sólo le permiten el uso del oído para la lectura ajena; y de la lengua para dictar alguna otra cosilla. Con efecto, conserva todavía su cabeza bien organizada sin decadencia de memoria. Estoy concluyendo la copia en limpio de la última parte de la Agricultura, y de aquí a diez o doce días iré diariamente a su posada a hacérsela, haciendo al mismo tiempo el cotejo con el texto en los lugares que a Su Excia. parezca. ¡Oh, cuánto celebraría (si fuese posible) que nuestro Maestro Sousa asistiese a esta revisión y cotejo!, como asistió al examen de la primera parte un tal P. Cañes, autor de un Diccionario Hispano-Arábigo, que falleció dos años ha ${ }^{2}$. Los arabizantes de Lisboa harán grandes progresos al lado de un Maestro tan inteligente y celoso, como es el P. Sousa; a mí me sirvió mucho cuando estuve en su compañía. Supongo que los que están ahí empleados habrán sido también discípulos suyos. Desearía saber si han emprendido algún trabajo de este género, especialmente el que se halla destinado a esa Iglesia ${ }^{3}$.

Siento que por las cosas de ésta haya V. Excia. trabajado en vano; y no sé si el que jaceant sub arcano palatino consista en la persona que por muchos títulos debía promoverlas. Tengo este recelo, y no sé si será fundado. Pero sea de esto lo que fuere, lo que importa es que V. Excia. viva tranquilo, y que no se mortifique ni aflija su espíritu por cosas que no puede remediar. 
La Biblioteca del Sr. Velasco se vendió entera al Marqués de la Romana, título de Valencia ${ }^{4}$. No sé que viva en la Corte el Conde del Aguila, y me persuado que el pueblo de su continua residencia es Sevilla ${ }^{5}$.

El Borbón, autor de las Cartas a Masdeu no es pariente del Teniente General que cita V. Excia. Es hijo de un maltés que años pasados hizo aquí de medio intérprete de la lengua árabe. Es amigo mío en efecto y le propuse lo que $\mathrm{V}$. Excia. me encargaba; pero me dice que hasta ahora nada más ha descubierto relativo a ese Obispado que lo que ha publicado en sus cartas. Fuera de las que remití a V. Excia., ninguna más ha publicado ${ }^{6}$.

Quedo entendido en dirigir el cajón de libros al Sr. Don Vicente Ferrer Siqueira en Elvas, e irán en el primer viaje de Carreño. Cuando llegue este caso, volveré a escribir a V. Excia. incluyendo la lista de los que fueren y haya podido encontrar. Dios guarde a V. Excia. en buena salud los años de mi deseo.

B.l.m. a V. Excia. su más afectuoso y obligado servidor,

\section{José Banqueri}

Incluyo también la carta del P. M. Risco para el Sr. Profesor de la Universidad de Coimbra.

\section{NOTAS}

1 En Junta ordinaria del 12 de agosto de 1796, la Real Academia de la Historia había acordado admitir a Cenáculo entre sus individuos honorarios y así se lo comunica el Secretario de la Academia don Antonio de Company cuatro días después. El 11 de abril de 1798 el mismo Company agradecía a Cenáculo el envío de los manuscritos a que se refiere Banqueri, a saber: Suma Moral, de San Raimundo de Peñafort; Libro de Doctrina Scholarum y el De Consolatione Philosophiae de Boecio, y una Exposición de los siete Salmos Penitenciales. También envió una piedra con una inscripción del nombre y los atributos de Fernando IV de Castilla, y una medalla del Duque de Osuna. Tanto las cartas del Secretario, como la que también le envió el Director de la Academia, el duque de la Roca, han sido publicadas en el Catálogo de la correspondencia dirigida a Cenáculo, vols. I, págs. 193-6, II, págs. 217-8.

2 Fr. Francisco Cañes, O. F. M., además de ser autor de una Gramática Arábigo-española vulgar, y literal (Madrid, 1775), publicó un Diccionario Español Latino-Arábigo en que siguiendo el diccionario abreviado de la Academia se ponen las correspondencias latinas y árabes, para facilitar el estudio de la lengua arábiga a los misioneros, y a los que viajaren o contratan en Africa y Levante. Compuesto por el P. Fr. Francisco Cañes Religioso FranciscoDescalzo de la Provincia de S. Juan Bautista, sa ex-Definidor, Misionero y Lector que fue de Arabe en el Colegio de Damasco, individuo de la Academia de la Historia. Dedicado al Rey Nuestro Señor. Tomo Primero, A - D; Tomo Segundo, E-O; Tomo Tercero, $P$ - Z, Madrid: En la Imprenta de Don Antonio Sancha, 1787.

Acerca de esta obra puede verse el artículo de Elías Terés, «El diccionario español-lati- 
no-arábigo del P. Cañes», en Al-Andalus, XXI (1956), págs. 255-76, si bien desconoce la opinión que acerca de ella expresó Fr. Juan de Sousa a Cenáculo en una carta del 3 de noviembre de 1788: "O Vocabolario do P. ${ }^{e}$ Cansi [Cañes] de que avizáo a V. Excia. de Hispanha, náo he couza interesante; porque he feito a moderna, sem vogães, sem digestāo, e sem methodo. Elle não tem todas as vozes que se encontrâo no Golio, Gigio, e outros. Está cheio de sentenças, e adagios do uzo dos Orientảes modernos. Eu vi tres folhas já impressas da dita obra quando estive em Madrid, e aqui mesmo me disserăo que nāo tam grande acceitaçāo, porem como foi impresso á custa das barbas longas, nāo perde nada o author da obra. V. Excia. tem alguns deste genero que tem milhor acceitaçāo. A obra do Banqueri posto que não tenha vogães, ha de ter outra acceitaçāo, por ser obra traduzida de hum original dos mesmos nacionaes, e nâo feita por un curiozo». Fïganier, Ob. cit., pág. 229.

3 Desde su establecimiento por Cenáculo como institución conventual y después de diversas alternativas, el 12 de abril de 1795 la cátedra de lengua árabe del convento de Ntra. Sra. de Jesús de Lisboa, adquirió reconocimiento oficial, continuando Fr. Juan de Sousa al frente de la misma y teniendo como colaboradores suyos a sus discípulos Fr. José de San Antonio Moura y Fr. Manuel Rebelo da Silva. Sousa fallecería el 29 de enero de 1812, pero la escuela continuó gracias a la valía y a los méritos de Moura y Rebelo.

Debido a la importancia alcanzada por esta escuela y al hecho de que en 1834 la Biblioteca conventual de los Terceros fuese incorporada a la Academia de las Ciencias de Lisboa, hace que sea hoy esta institución la que en Portugal tenga mayor número de manuscritos árabes. En 1962 el profesor Douglas Morton Dunlop se lamentaba de que dicha colección no fuese debidamente conocida, hecho que atribuía a la no existencia de un catálogo impreso de sus fondos. Afortunadamente, este inconveniente ya está a punto de quedar superado, gracias al trabajo del Dr. Adel Y. Sidarus, cuya catalogación y descripción de dichos manuscritos ha comenzado a publicar la Academia de las Ciencias de Lisboa, Catálogo de Mantuscritos. Serie Vermelha. I (Nüms. 1.499) (Lisboa, 1978).

Una recientísima aportación de nuevos datos para un mejor conocimiento de la historia del arabismo portugués durante este período es el artículo de María Francisca de Oliveira Andrade y António Alberto Banha de Andrade, «Subsídios para a história da aula de árabe no Convento dos Terceiros de S. Franciscon, en el Boletim da Biblioteca da Universidade de Coimbra, vol. XXXIV, $3 .^{\mathrm{a}}$ parte.

4 De la biblioteca del Marqués de la Romana se imprimió años después un Catálogo de la Biblioteca del Excmo. Sr. D. Pedro Caro y Sureda, Marqués de la Romana, Capitán General del Ejército y General en jefe, que fue, de las Tropas Españolas en Dinamarca el año de 1807. Trasladada a esta Corte desde Palma de Mallorca. Madrid: Imprenta a cargo de Francisco Roig, 1865. Hoy forma parte de los fondos de la Biblioteca Nacional, a la cual fue incorporada el año 1873.

5 Cenáculo habia conocido al conde del Aguila en la primavera del año 1768, a su paso por Sevilla.

6 Domingo o Faustino Muscat o Borbón había sido copiante o escribiente de árabe en la Biblioteca Real desde 1754 hasta noviembre de 1760, no figurando, en la plantilla de sus empleados por algunos años, hasta que vuelve a reaparecer entre 1784 y 1793 . Con el ánimo de ayudar a Juan Francisco Masdeu (1744-1817), quien en 1781 había comenzado a publicar una Storia Critica di Spagna e della cultura spagnola, publicó Muscat o Borbón unas Cartas para ilustrar la España Arabe. Cronicón del Pacense con notas. Madrid, 1796, obra fantástica, basada en fuentes históricas ficticias, por la que Cenáculo se interesaba. De este curioso personaje se ocupa Manuela Manzanares de Cirre, Arabistas españoles del siglo XIX (Madrid: Instituto Hispano-Arabe de Cultura, 1972), págs. 46-7. 
Excmo. Sr. Obispo de Beja

Muy Señor mío de toda mi veneración y cordial afecto: Por tener que pasar al sitio de Aranjuez a dar cuentas de la conclusión de la segunda parte de mi obra, me adelanto a decir a V. Excia. que a principios de Mayo saldrá de aquí Carreño con el cajón de los libros, rotulado y dirigido al Sr. Don Vicente Ferrer de Siqueira, en Elvas; y un sobre mío queda en el cuidado de entregarlo cuando vuelva de su lugar para hacer su viaje a Lisboa. Van todos los libros encargados, menos algún otro que no se encuentra, o por no haberse publicado todavía. Del Teatro de las Iglesias de Aragón por Fr. Rafael de Huesca falta el primero y segundo tomo, y por eso no he querido comprar esta obra incompleta ${ }^{1}$. Las Láminas que contienen las Plazas de Portugal ya no se encuentran; como ni el Specimen de prima typographiae hispanicae aetate ${ }^{2}$, ni el Sedulius et Juvencus de Arévalo ${ }^{3}$. De la obra Clarorum Hispanorum Opuscula Selecta de Cerdá, no se ha publicado más tomo que el primero que ya tiene V. Excia. ni hay esperanzas de que el editor publique más opúsculos ${ }^{4}$. Del Masdeu sólo se han publicado hasta ahora los 56 tomos que tiene V. Excia., ni más cartas de Borbón que las que fueron en el último cajón de septiembre.

Nuestro Muñoz me dijo que ya había contestado a V. Excia. y por eso su carta no fue con las demás inclusas del Director y Secretario de nuestra Academia. La traducción castellana de los Anales de Tácito por el Anagranmatario me encargué de cotejarla con la impresa que él supone o fuera del reino, o donde no es natural el castellano, como en Cataluña, Vizcaya, etc., y aún no he podido dar con esta edición para hacer dicho cotejo y dar cuenta a la Academia de mi comisión. El Anagranmatario supone en su Prólogo que la edición de su traducción nueva tiene algunos errores de prensa, quizás por no haberla él corregido.

Se ha publicado una carta de un ex-Jesuita de Roma en la cual impugna a Muñoz criticando su primer tomo del Nuevo Mundo. Yo aún no la he visto; pero me dicen que la crítica de este impugnador es demasiado dura y elesatenta. Muñoz, aunque ya la tiene, dice que no ha querido leerle todavía ${ }^{5}$.

Nuestro Cronista Fr. Pedro de Salas me pregunta por V. Excia. y espera que lo dirija con sus luces. El es sumamente aplicado, verdadero religioso y de un carácter amable. De nuestro Sánchez Sobrino nada sé, 
pues desde que fallecieron los desgraciados Padres no me ha escrito un renglón.

Finas expresiones y muchas saudades a mi amado Rvdmo. Sr. Padre Soledade su hermano y a los amigos de mi conocimiento. Dios me guarde la preciosa vida de V. Excia. muchos años.

B.l.m. a V. Excia. su más af ectuoso amigo, atento y obligado servidor y capellán,

\section{José Banqueri}

El Excmo. Sr. Conde de Campomanes repite a V. Excia. sus cordiales afectos.

\section{NOTAS}

1 Teatro Histórico de las Iglesias del Reyno de Aragón... Su autor el P. Fr. Lamberto Zaragoza, continuando por Fr. Ramón de Huesca. Los tomos I al VIII se imprimieron en Pamplona en la Oficina de D. Josef Miguel de Ezquerro y el IX en Zaragoza en la Oficina de Miedes. Los cuatro primeros tienen por autor a Zaragoza y los cinco restantes a Huesca, ambos capuchinos.

2 Raymundo Diosdado Caballero, S. J., De Prima Typographiae Hispanicae aetate spe. cimen. Romae: Apud Antonium Fulgonium, 1793. De esta obra se imprimiría la siguiente traducción castellana: Breve examen acerca de los primeros tiempos del arte tipográfico en España. Versión castellana por Don Vicente Fontán. Madrid: Oficina Tipográfica del Hospicio, 1865.

3 Caius Vettius Aquilinus Juvencus, Historiae Evangelicae Libri IV. Eiusdem carmina dubia, aut suppositicia ad mss. codices Vaticanos, aliosque, et veteres editiones recensuit Faustinus Arevalus. Romae: Apud Antonium Fulgonium, 1792.

Caius Coelius Sedulius, Opera Omnia. Ad mss. cod. Vaticanos, aliosque, et ad veteres editiones recognita. Prolegomenis, scholiis, et appendicibus illustrata a Faustino Arevalo. Romae: Apud A. Fulgonium, 1794.

4 Con la impresión de este volumen, primero y único de una frustrada serie de ellos, se pretendía reproducir, según refiere Palau, «obras raras y de poco cuerpo, algunas olvidadas y otras casi perdidas", con el ánimo de satisfacer una de las necesidades más sentidas por los ilustrados españoles, cual era la de revalorizar a los autores españoles del siglo de oro, frente a la fuerte invasión de autores y modelos extranjeros.

5 Francisco Iturri, jesuita criollo expulso, nacido en Buenos Aires en 1738, acababa de publicar, efectivamente, una Carta crítica sobre la Historia de América del Señor D. Juan Bautista Muñoz, Madrid, 1798, la cual se reimprimiría en Buenos Aires en 1818. Muñoz, claro que sí, terminó por leerla, publicando a continuación su Satisfacción a la Carta Crítica sobre la Historia del Nuevo Mundo. Valencia, Orga, 1798, escrito al que volvió a responder el jesuita en una Carta Segunda en que se contiene la crítica de la Historia del Nuevo-Mundo de don Juan Bautista Muñoz... Por M. A. R. F. Con licencia. Madrid, Año de 1798. 
ANEXO

NOTA DE LOS LIBROS CONTENIDOS EN EL CAJON*

\begin{tabular}{|c|c|c|c|c|c|}
\hline & & Formato & Tomos & $\begin{array}{l}\text { Encua- } \\
\text { derna- } \\
\text { ción }\end{array}$ & $\begin{array}{c}\text { Precio } \\
\text { en } \\
\text { reales }\end{array}$ \\
\hline 1 Bargas & $\begin{array}{l}\text { Discurso sobre la nobleza de } \\
\text { España }\end{array}$ & $4 .^{\circ}$ & & pasta & 22 \\
\hline 1 & El hombre en la agonía & $8 .^{\circ}$ & & $"$ & 7 \\
\hline 1 Ortiz & $\begin{array}{l}\text { Compendio de la Historia de } \\
\text { España }\end{array}$ & & $\begin{array}{l}4 \\
4\end{array}$ & $\begin{array}{l}\text { rústica } \\
\text { rústica }\end{array}$ & $\begin{array}{l}62 \\
62\end{array}$ \\
\hline 1 Altieri & Philosophia & $8 .^{\circ}$ & 4 & pasta & 52 \\
\hline 1 Zúñiga & Anales de Sevilla & $8 .^{\circ}$ & 5 & $"$ & 110 \\
\hline 1 Gimberniam & Modo de curar la hernia & $4 .^{\circ}$ & & rústica & 8 \\
\hline l Caviam & Apología de la Teología & $4 .^{\circ}$ & 6 & pasta & 138 \\
\hline 1 Idem & Defensa de dicha obra & $4 .^{\circ}$ & & $"$ & 26 \\
\hline 1 Méndez & Thipographia española & $4 .^{\circ}$ & & rústica & $\cdot$ \\
\hline 1 & $\begin{array}{l}\text { Diccionario de las Ordenes } \\
\text { Religiosas }\end{array}$ & $4 .^{\circ}$ & 2 & pasta & 44 \\
\hline 1 Eximeno & Del origen de la música & $8 .^{\circ}$ & 3 & $"$ & 69 \\
\hline 1 Idem & Duda del P. Eximeno & $8 .^{\circ}$ & & - & 23 \\
\hline 1 Cardillo & $\begin{array}{l}\text { Compendio de la historia } \\
\text { de Rusia }\end{array}$ & $4 .^{\circ}$ & & $»$ & 18 \\
\hline $\begin{array}{l}\text { 1 Huesca } \\
\text { (Rafael) }\end{array}$ & $\begin{array}{l}\text { Discurso de las Exequias de } \\
\text { Quinto Séptimo }\end{array}$ & $4 .^{\circ}$ & & rústica & 4 \\
\hline $\mathbf{I}$ & $\begin{array}{l}\text { Reflexiones politicas sobre el } \\
\text { estado religioso }\end{array}$ & $8 .^{\circ}$ & & pasta & 7 \\
\hline 1 Latasa & $\begin{array}{l}\text { Biblioteca de los escritores } \\
\text { aragoneses }\end{array}$ & $4 .^{\circ}$ & 2 & $"$ & 40 \\
\hline 1 & $\begin{array}{l}\text { Disertación sobre el Teatro de } \\
\text { Sagunto }\end{array}$ & $4 .^{\circ}$ & & rústica & 8 \\
\hline 1 Lumiares & Instrucciones de Cartago & $4 .^{\circ}$ & & pasta & 15 \\
\hline 1 Conde & Poesias de Safo & $8 .^{\circ}$ & & $"$ & 8 \\
\hline l Salmerón & Antigüedades de Cieza & $4 .^{\circ}$ & & perg. & 14 \\
\hline l Idem & De benignitate et opinando & $4 .^{\circ}$ & & $"$ & 15 \\
\hline 1 & Historia de Don Manuel Freira & $8 .^{\circ}$ & & rústica & 4 \\
\hline 1 & España en la mano & $8 .^{\circ}$ & & " & 2 \\
\hline 1 & Honor Español & $8 .^{\circ}$ menor & & " & 18 \\
\hline 1 & $\begin{array}{l}\text { Plan de un viaje para reformar } \\
\text { archivos }\end{array}$ & $4 .^{\circ}$ & & $"$ & 5 \\
\hline 1 & Oración Fúnebre del P. Scio & $4 .^{\circ}$ & & $"$ & 3 \\
\hline 1 Velázquez & Origen de la Poesía castellana & $4 .^{\circ}$ & & $"$ & 10 \\
\hline I Macanaz & Defensa de la Inquisición & & 2 & perg. & 12 \\
\hline 1 Guarinos & Biblioteca española & $8 .^{\circ}$ & 3 & pasta & 66 \\
\hline 1 Andrés & Carta de la literatura de Viena & $8 .^{\circ}$ & & perg. & 6 \\
\hline 1 Risco & España Sagrada & & 3 & $"$ & 46 \\
\hline
\end{tabular}




\begin{tabular}{|c|c|c|c|c|c|}
\hline & & Formato & Tomos & $\begin{array}{l}\text { Encua- } \\
\text { derna- } \\
\text { ción }\end{array}$ & $\begin{array}{l}\text { Precio } \\
\text { en } \\
\text { reales }\end{array}$ \\
\hline l Villodas & $\begin{array}{l}\text { Antigüedades eclesiásticas de } \\
\text { España }\end{array}$ & & 2 & pasta & 24 \\
\hline 1 & $\begin{array}{l}\text { Homilía sobre la libertad } \\
\text { christiana }\end{array}$ & $8 .^{\circ}$ & & rústica & 4 \\
\hline 1 & Exito de la muerte de Voltaire & $8 .^{\circ}$ & & pasta & 10 \\
\hline I Horatio & Humani regendi & $4 .^{\circ}$ & & $»$ & 14 \\
\hline 1 & Quaresma del P. Trento & & 4 & pasta & 84 \\
\hline 1 & Canal imperial de Aragón & fol. & & $»$ & 100 \\
\hline 1 Rosell & Sermones & $8 .^{\circ}$ & 2 & perg. & 24 \\
\hline 1 Cangas & Poesías de Safo & $4 .^{\circ}$ & & & 15 \\
\hline 1 & $\begin{array}{l}\text { Compendio de los Reyes de } \\
\text { Aragón }\end{array}$ & & 2 & pasta & 28 \\
\hline 1 & $\begin{array}{l}\text { Los tomos } 16 \text { y } 17 \text { de la Biblia } \\
\text { Sacra latina y castellana, } \\
\text { pagados el } 18 \text { y el } 19 \text { en pasta }\end{array}$ & & & & 62 \\
\hline & Cajón para dichos libros & & & & 20 \\
\hline
\end{tabular}

José Francisco Ortiz Sanz, Compendio cronológico de la historia de España desde los tiempos más antiguos hasta nuestros días. Madrid: Imprenta Real-Imprenta M. Repullés, 17951803, 7 vols.

Laurentio Altieri, O. F. M. Conv., Elementa Philosophiae in Adolescentium usum ex probatis autoribus adornata a F. Laurentio Altieri, Min. Conv. in Patrio Ferrariensi Lyceo Sacrae Teologiae Publico Professore... Editio nova Veneta ad Auctore recognita, novisque additionibus illustrata. Venetiis, M.DCC.XCIII. Typis Modesti Fenzii, Superiorum permissu.

Diego Ortiz de Zúniga, Annales eclesiásticos y seculares de la muy noble y muy leal ciudad de Sevilla, metrópoli de la Andalucía, que contiene sus más principales memorias desde el año de $1246 \ldots$ Formados por Don Diego Ortiz de Zúñiga, ilustrados y corregidos por D. Antonio María Espinosa y Carzel. Madrid, 1795-1796.

Antonio Gimbernat y Arbós, Nuevo método de operar la hernia crucial. Madrid: Viuda de Ibarra, 1793.

Francisco Méndez, O. S. A., Typographia española o Historia de la introducción, propagación $y$ progresos del arte de la Imprenta en España. A la que antecede una noticia general sobre la imprenta de la Europa, y de la China: adornado todo con Notas instructivas y curiosas. Tomo I. Madrid: Viuda de Joachín Ibarra, 1796.

Diccionario de las Ordenes Religiosas y Militares. Madrid, 1792.

Antonio Eximeno, S. J., Del origen y reglas de la Música con la historia de sus progresos, decadencia y restauración. Obra escrita en italiano... y traducida... por D. Francisco Antonio Gutiérrez. Madrid: Imprenta Real, 1796.

Duda sobre el Ensayo fundamental práctico del contrapunto del P. Fr. Juan Bautista Martini. Traducido del italiano por Francisco Antonio Gutiérrez. Madrid: Imprenta Real. Por D. Pedro Julián Pereyra, 1797.

Félix de Latassa y Ortín, Biblioteca antigua de los escritores aragoneses que florecieron desde la venida de Christo hasta el año 1500. Zaragoza: Oficina de Medardo Heras, 1796, 2 vols. 
Antonio Valcárcel y Pascual del Pobil, conde de Lumiares, Inscripciones de Carthago Nova, hoy Cartagena, en el Reyno de Murcia. Madrid: Imprenta de Sancha, 1796.

José Antonio Conde, Poesías de Saffo, Meleagro y Museo, traducidas del griego por... Madrid: Benito Cano, 17.

Pascual Salmerón, O. F. M., Antigüedades de Cieza antes Carteya, Ciudad Capital de la Olcadia, hoy Villa del Reyno de Murcia; Ilustradas con nuevas luces, que destierran las tinieblas con que las obscurece el moderno autor de la Bastitania y Contestania del Reyno de Murcia. Murcia: En la Oficina de la Viuda de Teruel, 1796.

De Benignitate in opinando Antiquorum Sapientum, Doctrinis, tum laxis, tum rigidis moderno tempore obscurata, et in pristinam lucem, ac integritatem restituta. Dissertaio Juridica, Legalis, et Canonica, et Theologico-Moralis, utriusque Juris Legibus, Regulis, et textibus SS.PP. et Antiquorum Theologorum auctoritatibus, novisque rationibus, et animadversionibus stabilita et roborata. Murcia: Manuel.

El honor español o historia del valor y del heroismo de la nación española por D. P. M. O. Madrid: Viuda de Marín, 1796.

Cayetano de San Andrés, Sch. P., Oración fúnebre en las Escuelas Pías del Avapiés de esta Corte en el $1 .^{\circ}$ de Mayo del presente año de 1796, que a la buena memoria del P. Phelipe Scío de San Miguel, Ex-Provincial del dicho Sagrado Orden, Obispo de Segovia, etc. Madrid: Benito Cano, 1796.

Luis José de Velázquez de Velasco, marqués de Valdeflores, Orígenes de la poesía castellana. Málaga: Por los herederos de F. Martínez de Aguilar, 1754. Tuvo una segunda edición en 1797.

Melchor Rafael de Macanaz, Defensa crítica de la Inquisición contra los principales enemigos que la han perseguido y persiguen injustamente. Dálas a la luz D. Antonio Valladares de Sotomayor. Madrid: Antonio Espinosa, 1798.

Juan Sempere y Guarinos, Ensayo de una biblioteca de los mejores escritores del Reynado de Carlos III. Madrid: Imprenta Real, 1785-1789, 6 vols.

Juan Andrés, S. J., Carta del abate D. Juan Andrés a su hermano D. Carlos Andrés, dándole noticia de la literatura de Viena. Madrid: Imp. de Sancha, 1794.

La publicación de la España Sagrada había sido iniciada por el P. Enrique Flórez, O. S.

A. (1702-1773) en 1747, llegando a imprimir en vida hasta el tomo XXVII y dejando manuscritos los tomos XXVIII y el XXIX, cuya publicación corrió a cargo del también agustino P. Manuel Risco (1735-1802). Este, a su vez, continuó la obra, redactando los tomos XXX al XLIII.

Manuel Villodas, O. M., Análisis de las Antigüedades eclesiásticas de España para instrucción de los jóvenes. Comprende los sucesos más notables de los once siglos primeros. Valladolid: Vda. e Hijos de Santander, 1796-1797.

El Exito de la muerte correspondiente a la vida de los tres supuestos héroes del siglo XVIII, Voltaire, D'Alambert y Diderot, demostrado con la simple, y verdadera narración de su muerte... Traducido del idioma francés al italiano y de éste al castellano por D. José Domenichini. Madrid: Imp. de J. Doblado, 1792.

El conde de Sástago, Descripción de los Canales Imperial de Aragón y Real de Tauste dedicada a Los augustos soberanos Don Carlos IV y Doña María Luisa de Borbón. Zaragoza: Francisco Magallón, 1796.

Obras de Sapho, Erinna, Alcman, Stesicoro, Alceo, Ibico, Simonides, Bachilides, Archiloco, Alpheo, Pratino, Menalipides. Traducidas del griego en verso castellano por D. Joseph y D. Bernabé Canga Argüelles. Madrid: Sancha, 1797.

La Biblia vulgata latina, traducida por el P. Phelipe Scío de San Miguel de las Escuelas Pías. Segunda edición, revista, corregida y aumentada por el mismo traductor. Madrid: Benito Cano, 1794-1797. 
Excmo. y Rvdmo. Señor Obispo de Beja

Mi muy venerado Padre y especialísimo favorecedor. La muy apreciable de V. Excia. de 18 de abril ha llenado mi alma de gozo, y respiro con ella del cuidado en que me tenía el dilatado silencio de nuestro Sousa y del amigo don José Cornide, por quienes al principio tenía yo más frecuentes noticias de V. Excia. Pero de un año o más a esta parte uno y otro han callado, no obstante que el último me debía una o dos cartas; bien que me persuadía, que sus expediciones y ocupaciones literarias no se lo permitían, y más cuando por medio de otro amigo de nuestra Academia me anunció que no lo había hecho hasta entonces porque se proponía escribirme con extensión para que en su carta informase yo a nuestro Director el Excmo. Sr. Conde de Campomanes del progreso y resultado de su comisión literaria; of erta, que aún hasta el presente parece no ha podido desempeñar ${ }^{1}$.

Siento en mi corazón que V. Excia. lo haya pasado tan mal, y que en todo el año anterior le hayan acometido esas porfiadas y crueles tercianas, de que deseo convalezca $V$. Excia. perfectamente sin peligro de que vuelvan a molestarle. Tampoco lo pasé yo muy bien ese mismo año, mortificándome mucho cierta opresión al pecho; la cual yendo en aumento llegó casi al último grado a fines de enero de este año, de manera que estando en bastante inminente peligro de mi vida, recibí el 8 de febrero los Santos Sacramentos. Pero (a Dios gracias) con el beneficio de repetidas y copiosas sangrías, y de cinco crueles parches de cantáridas, se desarmó la peligrosa enfermedad, de que estoy cerca de convalecer perfectamente con la leche de burra que estoy tomando. Esta es la causa de no haber escrito a V. Excia. cuando (escaseándome noticias los dos expresados amigos) ardía en deseos de saber de su salud y de sus cosas. Estos incidentes han ocasionado también el atraso de la impresión de la segunda parte de la Agricultura, e impedido que se acabase en este mes o principios del siguiente, como yo creía, por las pausas que ha sido necesario interponer en este trabajo. No obstante, van ya tirados 130 pliegos, y sólo restarán poco más de 40 sin el Discurso Preliminar de la obra, que estoy ya trabajando, y cuya mitad en borrador ha leído el ilustre Censor el Sr. Campomanes. El dictamen de este señor irá también a la frente de ella, como una piedra preciosa o esmalte, que no dejará de preservarla de los tiros de algunos malignos o mal intencionados. Pienso que podrá estar la obra en disposición de publicarse en todo octubre a más tardar. Como parece regular que al traductor y editor 
conceda la Biblioteca Real (de cuya cuenta se imprime), o más bien el Rey, media docena de ejemplares lo menos, V. Excia. es el primer acreedor por tantos títulos a que yo tenga el gusto y el honor de presentarle un ejemplar. Otro irá para nuestro Sousa, y (si puede ser) otro para la Librería de nuestro convento de Jesús. Con los restantes cumpliré con algún otro amigo, que han contribuido con sus alientos, auxilios y favores a la continuación de la obra (como es el Sr. Saavedra, Ministro lastimosamente retirado, y que ahora reside en el Puerto de Santa María) y que la han defendido para que no sufriese el naufragio que se proponían algunas personas émulas.

Hasta ahora no he tenido ni podido tener parte en la preparación de la Colección de Cánones para su impresión. De hoy en adelante podré tenerla, pues siendo éste una especie de fidei comiso literario, que me dejó el insigne Casiri, yo debería ser el instrumento de su publicación. Pero hasta ahora no sé que los jefes de la Biblioteca hayan pensado que yo tenga en ello parte, aunque el Sr. Campomanes (hecho cargo de la rivalidad del Cuerpo) piensa hablar de esto al nuevo Bibliotecario Mayor don Antonio de Vargas, luego que se concluya la impresión de la obra de Agricultura. Sea de esto lo que fuere, siempre tardará mucho tiempo en comenzarse la impresión de una y otra Colección Arábiga y Gótica, aún cuando hubiese continuado de Mayor en la Real Biblioteca don Pedro Luis Blanco, autor de la carta que ha visto V. Excia. Este se halla al presente electo Obispo de León, después de haber sido algunos meses de Albarracín. ¿Quién creería que el autor de esta carta hubiera tenido al principio por inútil la impresión de la preciosa Colección arábiga de los Cánones? Pero mudó de opinión después que vio el grande aprecio que en el Ministerio se hacía de la Primera Parte impresa de la Agricultura, y las muestras públicas que de ello se dieron con la Prebenda de la Iglesia de Cartagena con que el Rey premió y honró al traductor, continuando lo mismo con la Dignidad de Prior Claustral de Tortosa. ¿Quién creería, que el mismo autor de la carta expresada hubiese solicitado dos años ha, por medios muy irregulares e indecorosos, que se me retirase de la Biblioteca, en la que (según expresión al Ministro) para nada me necesitaba? Y, ¿quién podría creer que recién concluida la revisión y examen de la segunda parte por el Sr. Conde, y cuando se trataba de imprimirla en continuación de la primera, pasase aquél oficios a la imprenta Real, para que no se procediese a la impresión, valiéndose de vanos pretextos, y que para disiparlos y desvanecer tan infundados impedimentos, fuese necesario toda la autoridad y opinión del Conde de Campomanes? Pues así ha sucedido, puntualmente. Sic sunt homines. Pero dejemos materias tan ingratas, y pasemos a otra $\cos \mathrm{a}^{2}$. 
Las 16 monedas que V. Excia. me envía por medio de nuestro Sousa exceden a la cuenta de los libros que remití; y aunque no tengo ésta ahora presente, me parece que han de quedar para la siguiente mucho más de 600 , o cerca de 700 reales. A don Manuel Villena entregué ayer las ocho monedas, y quedó en escribirle las gracias luego que se restablezca de unas pesadas tercianas que hace muchos años le molestan ${ }^{3}$.

El difunto amigo Muñoz no tendrá sucesor por ahora en su comisión; pues habiéndose ofrecido a continuarla nuestra Academia, la resolución superior ha sido que se suspenda. Mirum!

Hace muchos días que no he tenido carta del P. Cronista Fr. Pedro de Salas. Pero hoy mismo le escribo participándole la especie que me encarga V. Excia. sobre los dos Sres. Obispos, naturales de Hibernia, que fueron sepultados en el convento de Jesús.

No sé que a Presbítero alguno francés se haya respondido por el Sr. Arce, Arzobispo de Burgos e Inquisidor General, sobre Sínodo de aquella Nación. Persuádome, que la noticia que han dado a V. Excia. es equivocada. Lo que hay en esto es, que un tal Gregoire, Obispo Constitucional de Blois, destacó meses pasados a varias personas de esta Corte algunos ejemplares de una carta traducida al español ${ }^{4}$, y escrita en francés y dirigida por el mismo al Inquisidor General, en la que indecorosamente vomita máximas contra el Tribunal de la Inquisición, con el fin al parecer de que el gobierno procure echarle por tierra, y con el pretexto o pretendido celo no sólo de fomentar y adelantar por este medio en España la buena literatura, sino también de sentar sobre bases firmes la libertad evangélica, que el autor de la carta pretende y supone haber tiranizado dicho Tribunal. A esta carta se respondió (no sé si por encargo del Dr. Arce) con dos papeles, uno escrito por el mencionado Sr. Blanco ${ }^{5}$, y el otro por un Villanueva, Doctoral del convento de estas monjas de la Encarnación ${ }^{6}$. Si V. Excia. no tiene estos dos papeles, irán con los libros que tiene que encargarme; y lo mismo la segunda parte de las Rentas de la Iglesia de España, si se hubiere publicado (lo cual ignoro). También irán los dos últimos tomos de la Biblia del P. Scío, que se han publicado y tengo en mi poder.

Aunque los franceses se entienden con España, y no con Portugal, aquí se ignoran sus cosas punto menos que ahí; y lo poco que se sabe tiene dividido al público español en opiniones. Unos abominan a los franceses; otros los quieren y defienden con calor; los cuales creen que han de ser los autores de la paz y tranquilidad, que tanto necesita la trabajada y afligida Europa; y que el gran promotor de esto es el primer Cónsul Bonaparte, 
quien (según los primeros) bajo este especioso título se ha arrogado desvergonzadamente la soberana autoridad, tiranizando aquella República. Sólo el tiempo puede ilustrar la obscuridad de tantas dudas, y desvanecer tantas confusiones en las ideas políticas. Nada se sabe por acá sobre la ida del nuevo Papa a Roma; la cual se cree que no podrá tener efecto hasta la deseada paz general.

El Sr. Campomanes repite a V. Excia. sus respetos, y cordiales afectos y yo hubiera deseado que la carta que V. Excia. entregó al Sr. Cornide me la hubiese incluido a mí, respecto a que Cornide tiene que pasar, o ya habrá pasado a La Coruña, antes de regresar a Madrid, hasta cuyo tiempo carecerá este Señor de la satisfacción que le dará la carta de V. Excia.

He envidiado muchas veces la suerte feliz del amigo Cornide en disfrutar de tan buenos ratos en el dulcísimo trato de V. Excia. y así me lo anunciaba a los principios, explicándose con tanta verdad como entusiasmo. Pero, icuándo se me proporcionará a mí semejante fortuna! Mis ocupaciones y mi destino me quitan la libertad de salir de Madrid, y el pedir licencia para ello, podría traer algunos inconvenientes, como V. Excia. mismo se hará cargo. Con todo, siempre mantengo la esperanza de que Dios los dispondrá por algún medio extraordinario e imprevisto, y cuando menos se piense. $O$ utinam! Entre tanto, disponga V. Excia. de toda mi buena voluntad, debido obsequio, y pronta obediencia, dispensándome los apreciables preceptos que fueren de su agrado. Dios me guarde la preciosa e importante vida de V. Excia. los muchos años que deseo y pido al Sr. en mis tibias oraciones.

Excmo. y Rvdmo. Señor, b.l.m. de V. Excia. su más afecto y obligado servidor,

José Banqueri

\section{NOTAS}

1 El insigne historiador, arqueólogo y secretario de la Real Academia de la Historia don José Cornide Saavedra se encontraba en Portugal desde octubre de 1798, comisionado por la misma Academia para copiar un códice de las Siete Partidas de Alfonso X el Sabio que se conservaba en la Torre do Tombo. Con ocasión de este viaje Cornide efectuó una gira por todo el territorio portugués, durante la cual tuvo oportunidad de conocer personalmente a Cenáculo, las impresiones de cuyo encuentro pueden leerse en el tomo III del Estado de Portugal en el año 1800 , así como también la correspondencia que le envió a Cenáculo. Sobre este viaje de Cornide y sus relaciones con Cenáculo puede verse el artículo de Amado Ricón Virulegio, «As 
dúas facianas do viaxe de don Xosé Cornide a Portugal», en Grial, Revista Galega de Cultura, N. ${ }^{\circ} 25$ (1969), págs. 308-324.

2 Estas reflexiones de Banqueri acerca de la publicación de la Colección Arábiga de los Cánones de la Iglesia Hispana vienen motivadas por la lectura, por parte de Cenáculo, de la Noticia de las Antiguas y Genuinas Colecciones Canónicas inéditas de la Iglesia Española, que de orden del Rey Nuestro Señor se publicarán por su Real Biblioteca de Madrid, dedicada a S.M. y dispuesta por su Bibliotecario Mayor Don Pedro Luis Blanco. Madrid en la Imprenta Real. Por D. Pedro Pereyra, Impresor de Cámara de S.M. Año de 1798.

3 Manuel de Villena y Mouziño, arqueólogo español relacionado con Cenáculo, al cual se había ofrecido para venderle algunas de sus piezas. Villena fallecería en Madrid el 10 de noviembre de 1802. Sus cartas a Cenáculo en la Biblioteca Pública de Evora, CXXVII/2-9, Núms. 3807-3822.

4 Carta del ciudadano Gregoire, Obispo de Blois, representante del pueblo francés a Ramón Josef de Arce, Arzobispo de Burgos, Inquisidor General de España. París, 1798. También fue publicada en francés, en cuyo idioma tuvo al menos cuatro ediciones, la última de ellas en 1824.

Respuesta pacífica de un español a la carta sediciosa del francés Gregoire, que se dice Obispo de Blois. Madrid en la Imprenta Real año de 1798. Por D. Pedro Pereyra, Impresor de Cámara de S.M.

Cartas de un presbitero español sobre la carta del ciudadano Gregoire, obispo de Blois, al señor arzobispo de Burgos, inquisidor general de España. Las publica don Lorenzo Astengo. Madrid: Cano, 1798. En este mismo año tuvo una segunda edición. El nombre completo de su autor era el de Joaquín Lorenzo Villanueva Estengo.

XI

Tortosa 25 de Octubre de 1801

Excmo. y Rudmo. Sr. Obispo Don Fr. Manuel del Cenáculo Vilas Boas

Muy Señor mío y amadísimo Padre y especial favorecedor: $\mathbf{A}$ fines del año anterior recibí la muy apreciable de V. Excia. inclusa en la de nuestro Sousa. Entonces estaba ya acabando de extender el Discurso preliminar de mi obra para que revisto y examinado por el mismo censor de ella el Excmo. Sr. Conde de Campomanes, se pasase a la imprenta, que era lo único que restaba por tirar la Dedicatoria al Rey y el dictamen de dicho Señor Censor. Esta fue la causa de no contestar a V. Excia. inmediatamente esperando asimismo, concluida que fuese la expresada ocupación, recoger los libros que V. Excia. me encargaba. Pero apenas di fin a este trabajo, y cuando se estaba reviendo dicho Discurso por el Sr. Conde, me hallé de improviso con un oficio del Ministro de Estado, por el cual se me ordenaba pasase a residir mi dignidad de Prior Claustral de esta Santa Iglesia, y aquí continuase los trabajos literarios de Biblioteca, en que estaba entendiendo. Todos los amigos, los celosos de la literatura, y los apreciadores de la obra quedaron 
asombrados, y aun escandalizados de tan intempestiva novedad, fomentada (según todos creen) por el Ministro de Gracia y Justicia Don José María Caballero, contrario declarado del Ministro de Estado anterior Don Francisco de Saavedra, antiguo e íntimo amigo mío y favorecedor, y que ha cerca de tres años que por la enfermedad que había padecido, o más bien por indignas rivalidades fue retirado del Ministerio.

Dos años estuvo espiando el Sr. Ministro Caballero la ocasión de que se me retirase de Madrid, y al cabo de este tiempo encontró un pretexto plausible en una visita inocente, inocentísima, que hice a un palaciego, llamado Don Manuel Mallo, persona favorecida de la Reina. Este sujeto había recibido, desde que vino de Caracas su patria, algunos favores de Saavedra, para quien traía recomendación, y aunque yo le había tratado las veces que casualmente concurríamos en casa de esta persona antes de ser Ministro y cuando era sólo Consejero de Guerra, después de la revolución última del Ministerio, acaecida tres años ha, nunca volví a ver a dicho Mallo, faltando ya la ocasión de encontrarme con él en casa del expresado amigo mío. Pero habiéndole encontrado casualmente en un ángulo del Palacio el último día del año anterior, me dio quejas muy sentidas de que no le hubiera visitado en tanto tiempo; siendo la conclusión instarme fuertemente a que le hiciese siquiera una o dos visitas. Alegándole yo mis ocupaciones, e insinuándole las razones o consideraciones políticas que yo tenía para no haberlo hecho ni hacerlo, no obstante que no dejó de conocer la prudencia y justicia de ellas, repuso: que por una o dos visitas no había de temer o recelar; y que sobre todo, tenía que comunicarme una especie importante o conducente para mi gobierno. Con esta salva y protesta, movido por otra parte de una al parecer prudente curiosidad, y temiendo asimismo incurrir en la nota de inurbano o grosero, si no le visitaba, me determiné a ello no sin cierto género de violento sacrificio, y con ef ecto le hice la visita a que tanto me instaba. Esta no llegó a cuarto de hora, y en ella me participó que el mencionado Ministro había solicitado mi retiro de Madrid; pero que hallándose él presente a esta gestión que hizo contra mí delante de la Reina, pudo frustrarla haciendo una exposición del carácter de mi genio retirado y nada intrigante y de los importantes y gloriosos trabajos literarios, en que estaba entendiendo ${ }^{1}$.

Pero lo que no pudo lograr entonces, lo consiguió después con el pretexto de esta inocente visita, hecha a una persona, a quien, dicen, se cela hasta el grado de que nadie absolutamente la visite ni hable en su casa; lo cual no me pareció creíble en manera alguna, aunque por muchos se 
afirmaba, por considerarlo especie injuriosa, y muy reprensiblemente calumniosa a la persona que le favorece.

En vista pues de la expresada orden para salir yo de Madrid a esta ciudad, supliqué al Sr. Campomanes se sirviese encargarse de todo lo respectivo a la obra en lo que restaba por tirar, hasta de la corrección tipográfica, exceptuando alguna otra prueba que yo, debía corregir aquí por contener textos árabes. Admitió su Excia. este encargo con mucho gusto, y en esta atención se comenzó el tirado de los preliminares de la obra. Pero el Sr. Conde con esta prudencia ha sido de parecer llevar la impresión con alguna pausa y lentitud, esperando por este medio, que variando tal vez las circunstancias por las mudanzas que se anunciaba habría en el Ministerio, acaso se ofrecerían otras más favorables en que pudiese promoverse mi regreso a Madrid para el efecto de concluir la impresión de mi obra, y tener la satisfacción y el honor de presentarla a SS.MM. Pero siguiendo hasta el presente el mismo estado de cosas y circunstancias, no sé cual será el resultado o suerte de ella. Si yo hubiese permanecido cuatro meses más en Madrid, estaría concluida y presentada en julio o agosto del año anterior.

El jefe anterior de la Real Biblioteca Don Antonio de Vargas, aunque sólo estuvo en ella poco más de un año, favorecía y hacía mucho aprecio de la obra, y se indignó del procedimiento usado conmigo aún más que yo ${ }^{2}$. Pero nada pudo remediar no hallándose ya de Bibliotecario Mayor por ser nombrado pocos días antes Embajador de Roma, para donde partió a poco de haber salido yo de Madrid (que fue el 24 de enero). Aquí he sabido que su sucesor en la Biblioteca Don Pedro de Silva, hermano del Marqués de Santa Cruz, determinó que se sacasen de la imprenta dos ejemplares de mi obra, y que ésta (aunque impresa) fuese de nuevo revisada por dos o tres arabizantes, que hay en la misma Biblioteca, sin saber si por encargo superior o por sugestión de los mismos compañeros míos, rivales de mi obra, ni para qué fin ${ }^{3}$. Sabido esto por el Sr. Conde Censor (a quien no deja de ser bastante injuriosa esta extraordinaria novedad) me encarga de su parte el amigo Cornide, que como noticioso de ella escriba yo al nuevo Bibliotecario Mayor, pidiéndole traslado de los defectos, errores o equivocaciones que se hayan notado en mi obra para formar un apéndice o fe de erratas, y darles corregidos al fin de cada tomo, o satisfacer a los reparos, que según mi dictamen carezcan de fundamento sólido. Así lo he hecho con fecha de 18 de este mes; pero yo dudo que aun conteste. En cuyo caso se me previene de parte del mismo Sr. Conde, que acuda con la misma justa pretensión al Ministro de Estado Don Pedro de Cevallos; lo que haré igualmente si no se me remite el traslado pedido al Bibliotecario Mayor. 
Si V. Excia. estuviese en esa Corte y en los términos que en otro tiempo, sería fácil disipar este nublado y tormenta levantada contra mí y contra la obra, interponiendo la alta protección y eficaz recomendación de los Serenísimos Señores Príncipes del Brasil para con sus amados padres, y no prevalecería en prejuicio del bien y gloria de la Nación la intriga y malevolencia de los autores de esta antiliterata novedad. No sé si a pesar de la ausencia de V. Excia. de la Corte, será posible agenciar tan benéfica recomendación y alta protección. Algo de esto indico a nuestro Sousa para que conferenciando el punto con V. Excia. vean si hay medio de reparar esta injuria, hecha no tanto a mí como a la literatura. De esta suerte podría yo emprender y promover la impresión y publicación de la Colección de Cánones que el ilustre Casiri dejó traducida al latín y cumplir la obligación que me impuso con sus encargos repetidos de que corriese yo con esta obra hasta su publicación (que fue como especie de fideicomiso literario), como todo consta al Sr. Campomanes que tiene los mismos deseos de que yo me emplease en este trabajo, concluido que fuese el de la Agricultura.

Aunque han pasado más de ocho meses que estoy en esta ciudad no he escrito antes a V. Excia.: primero, por poderle informar de lo que resultase respectivo a mi obra, como ahora lo hago; segundo, por los estorbos que para ello he tenido en dos repeticiones que he padecido de ataque al pecho (de que ya he convalecido casi perfectamente); tercero, por la guerra; y últimamente por la ocupación de algún Sermón del mayor empeño que se me había encomendado en esta Santa Iglesia y cuyo trabajo me ha sido tanto más difícil cuanto habían pasado casi 22 años que no había ejercitado el ministerio de la Divina Palabra ${ }^{4}$. Soy muy favorecido del P. Salinas, Obispo de esta Iglesia, no obstante los sucesos pasados en la Provincia de Andalucía y el poco favor que le debieron nuestros ilustres Mohedanos, mis amadísimos maestros ${ }^{5}$.

Con la repentina preparación de mi venida se quedaron con mis pocos libros, que dejé encajonados en Madrid, varios papeles que aquí me han hecho falta, y entre ellos la list a de los libros que V. Excia. me encargaba en su última carta. Espero que en la primera oportunidad me envíen estos papeles, y entonces remitiré dicha lista al amigo Cornide encargándole junte los libros que contiene, y disponga su remesa por la vía de Elvas, como $\mathrm{V}$. Excia. me prevenía. V. Excia. se servirá avisarme a mí o al mismo Cornide si quiere se compren algunos otros más que tengo apuntados, o dejarse de comprar algún otro de los contenidos en la lista, que tal vez haya adquirido V. Excia. posteriormente por otra parte. 
Muchas saudades al Rvdmo. Señor su amado hermano, a quien ruego a V. Excia. los felices y dilatados años de mi deseo.

Excmo. Señor, B.l.m. de V. Excia. su cordialísimo y obligadísimo servidor,

\section{José Banqueri}

\section{NOTAS}

Son bien conocidas la figura y vicisitudes de Manuel Mallo en la corte de Carlos IV y Fernando VII. Había nacido en Popayán (Nueva Granada) en 1771, en donde su padre, al parecer nacido en Galicia, era contador. La familia pasó a Caracas en 1775, en donde Saavedra era entonces Intendente. Nuestro Mallo pasó a Madrid en 1788 como cadete de la compañía americana de las guardias de corps; en 1798 se convirtió en "gentilhombre secreto en ejercicio y servidumbre de la Reina María Luisa", momento a partir del cual su nombre se añade a la lista de aquellos infaustos personajes en que sobreabundó la corte. Alberto Miramón, Dos vidas no ejemplares: Pedro Fermín de Vargas - Manuel Mallo (Bogotá: Academia Colombiana de Historia, 1962).

2 Antonio de Vargas y Laguna sólo Bibliotecario Mayor desde el 6 de julio de 1799 hasta el 16 de diciembre de 1800.

3 Pedro de Silva fue Bibliotecario Mayor desde el 16 de diciembre de 1800 hasta el 3 de abril de 1808 .

4 Se imprimió con el título de Oración en la solemnidad del descenso de María Santísima a la Santa Iglesia Catedral de Tortosa y de la entrega de su sagrado cíngulo a un piadoso sacerdote. Madrid: Hija de Ibarra, 1805.

5 Sobre Salinas, puede verse el artículo de Juan Meseguer, O.F.M., «El P. Antonio José Salinas, Comisario General de los Franciscanos y Obispo de Tortosa (1732-1815)", en Archivo Ibero-Americano, VI (1946), págs. 53-87.

\section{XII}

Tortosa 25 de Noviembre de 1802

Excmo. Señor Arzobispo de Evora, Don Fr. Manuel del Cenáculo y Vilas Boas

Muy Señor mío y mi más amado y venerado Padre: Ya nuestro Sousa diría de mi parte a V. Excia. la más afectuosa enhorabuena por su exaltación al Arzobispado de Evora, que yo hubiera celebrado más si hubiera sido muchos años antes ${ }^{1}$. La justa consideración de no ser importuno a un tiempo en que debía yo suponer a V. Excia. sumamente ocupado en la Corte y sin ocio para nada, me obligó a omitir por entonces la debida carta congratulatoria, persuadido por otra parte de que V. Excia. podía fácilmente 
conjeturar cuales serían los sentimientos festivos de mi corazón por un suceso tan plausible. ¡Dichosa Iglesia, que ha merecido tal Pastor en la persona de V. Excia, aunque le haya logrado tan tarde! Sin embargo, iqué bienes deberá aún esperar de las superiores luces y sabiduría de V. Excia. y de su activo celo verdaderamente apostólico! ¡Quiera el Señor (como se lo ruego) alargar la vida a V. Excia. cuanto interesa su nueva Grey y la República Literaria!

El extendido celo de V. Excia. le hacía desear mucho tiempo ha la publicación de la Colección Arábiga de los Cánones, traducida al latín por el célebre Casiri; y yo digo, que si V. Excia. levanta ahora la voz de ese celo mismo, haciendo ver la utilidad y gloria que resultaría a nuestra Iglesia de España de la publicación de tal obra, ciertamente se lograría que el jefe de la Biblioteca Real de Madrid, el Sr. Don Pedro de Silva recobrase el grado de aliento, que parece le falta, para poner en ejecución un pensamiento tan honorífico y glorioso, como es éste; y quizá estos solos clamores de V. Excia. auxiliados de la insinuación competente, que podría hacer esa Corte, contribuiría a que a mí se me diese esa comisión.

El difunto Casiri, mi Maestro, me hizo repetidas veces el encargo de que, si después de su fallecimiento se tratase de publicar esta preciosa Colección Canónica, repasase yo cuidadosamente la traducción latina que hizo de ella, cotejándola escrupulosamente con el texto original, y la corrigiese o mejorase dándola la última mano en los lugares que lo necesitase; y también que en su corrección tipográfica pusiese el mayor esmero. No ignoraba la Real Biblioteca este encargo (que también constaba al difunto Señor Conde de Campomanes); pero a algunos de mis compañeros, arabizantes y no arabizantes, émulos graciosos de mi obra de Agricultura no les acomodaba que fuese yo quien corriese también con dicha Colección.

De aquí ha venido que en mi ausencia de Madrid, y contra mi voluntad, hayan suprimido una larga nota (aunque impresa y tirada ya), que con aprobación, y aún por consejo del Sr. Campomanes había yo puesto en el discurso preliminar de mi obra; en cuyo texto publicaba esta especie de fideicomiso literario, que me dejó el expresado Casiri; la cual brevísima expresión también suprimieron. En esta nota procuraba yo ilustrar los dos puntos esenciales, respectivos al autor de la Colección Arábiga, y al mismo tiempo en que pudo o debió hacerse esta traducción; resultando de las reflexiones que yo hacía (deducidas o fundadas en dos notas arábigas que se leen el fin del tit. $7 .^{\circ} \mathrm{y}$ del $8 .^{\circ}$ del Códice de la Colección) ser especies equivocadas las contenidas en la Noticia de esta misma Colección y de las 
Góticas, que se publicó el año de 1798 y que V. Excia. creo ha leído ya. Con efecto, en esta Noticia se da por autor de la traducción arábiga de la Colección Canónica al que sólo fue un mero copiante del Códice del Escorial, y se atrasa la formación de esta Colección a mediados del siglo XI, siendo así que no pudo haberse hecho sino en el siglo IX, según opinaban los Señores Casiri y Campomanes, cuya opinión confirmaba yo en mi nota,

Vea aquí V. Excia. como las rivalidades injustas, y los intereses, y miras o consideraciones personales han sacrificado hasta el presente la utilidad y gloria de la Iglesia de España. Mis compañeros de Biblioteca han deslumbrado o preocupado al nuevo jefe el Sr. Don Pedro de Silva, representándole que la publicación de esta obra es nada importante. Por mi nota y la expresión del texto de mi Discurso preliminar suprimidas han visto que el trabajo hecho por el Sr. Casiri necesita de alguna corrección y lima; lo cual ellos ignoraban. Así, no quieren ellos entrar en este trabajo; ni quieren tampoco que yo entienda en él, verosímilmente por quitarme esta gloria, que ellos se figuran, y que yo de buena gana renunciaría desde ahora, atendiendo sólo a la que resultaría a la Nación Española y a su Iglesia, así como a la memoria de aquellos celosos Obispos Mozárabes, que fueron autores de tal pensamiento y de ejecución. El enemigo común se ha atravesado y ha auxiliado las intenciones de mis compañeros, como V. Excia. podrá conocer si tiene presente la relación que le hice en mi antigua última carta.

Pero parece, que Dios va disponiendo las cosas de otro modo. De vuelta de Barcelona se ha detenido la Corte tres días en esta ciudad, y he debido a algunos Señores Ministros del despacho muestras de aprecio para mi traducción de la obra de Agricultura del Mahometano de Sevilla. Ya llegó pues el tiempo oportuno de que V. Excia. obre conforme a su fervoroso celo, y según la proporción que tenga de interesar esa Corte en unos oficios tan importantes. Pasemos a otras cosas.

Ya sabrá V. Excia. que la citada obra de Agricultura quiso Dios que al fin se desprendiese de las cadenas que injusta y violentamente la oprimían, y triunfase de las críticas y oposiciones de los émulos que pretendían sepultarla, y que se publicó en la Gaceta de Madrid el 17 de agosto de este año ${ }^{2}$. Me propuse no molestar entonces a V. Excia. esperando para escribirle que se presentase ocasión de remitirle algunos ejemplares. Habiendo escrito sobre esto a nuestro Rvdmo. Sousa me avisa, que se dirija el cajón a Badajoz a la persona que V. Excia. le prevenía, y ya aviso a Madrid para que en la primera oportunidad se remita allí el cajón. En él irán cuatro 
ejemplares de mi obra; dos para V. Excia. y su digno hermano, y los otros dos para mis Maestros, el Rvdmo. P. Sousa, y el Rvdmo. Sr. Confesor de la Serenísima Sra. Princesa, si a V. Excia. le pareciere conveniente, pues yo no le he escrito ni le escribo nunca ${ }^{3}$. Asimismo va en el cajón el tomo tercero de Memorias de la Academia de la Historia, que yo había recogido poco antes de partirme de Madrid (el cual es regalo de la Academia); los últimos tomos de la Biblia del Iltmo. P. Scío, a que había suscrito a V. Excia., con un mapa; y cuatro tomitos de Sermones que regala a V. Excia. nuestro Sánchez del convento de Granada ${ }^{4}$.

Ruego a V. Excia. dé de mi parte al Rvdmo. Padre su amado hermano finísimas expresiones y también al Rvdmo. Sr. Padre Fr. Vicente Salgado y demás favorecedores míos. Dioş me guarde la importante vida de V. Excia. muchos y felices años.

Excmo. Señor, B.l.m. de V. Excia. su cordialísimo, atento y muy obligado servidor,

\section{José Banqueri}

\section{NOTAS}

1 Promovido a la archidiócesis de Evora en este año de 1802, Cenáculo permanecería en esta ciudad hasta su fallecimiento, el 1 de marzo de 1814.

2 La noticia de su publicación fue dada a conocer por la Gaceta en los siguientes términos: «Tratado de agricultura: su autor Abu Zacaria Iahia Aben Mohamed Ben Ahmed Ebn-el Awam, sevillano: traducido en castellano y anotado por D. Josef Antonio Banqueri, Prior claustral de la catedral de Tortosa, individuo de la Real biblioteca de S.M., y académico de número de la Real academia de la Historia: dos tomos en folio en árabe y castellano de más de 1500 páginas, impresos con todo esmero de orden de S.M. a expensas de su Real biblioteca. Esta obra, que propiamente es una colección de todas las máximas relativas a la agricultura, que hasta el siglo XII (en que se cree floreció el autor) dexaron escritas los autores españoles mahometanos, persas, africanos y latinos (de quienes ua un catálogo al principio del tomo $1 .{ }^{a}, y$ de que da razón en su prólogo el mismo autor), tiene la conocida ventaja de que como era español, diestro agricultor, y poseía además tierras en el alxarafe de Sevilla, teatro de sus experimentos, son todos sus preceptos muy acomodados a nuestro clima, e hijos de su propia experiencia: razones que más estimularon al traductor a emprender para beneficio de la nación un trabajo, tan improbo, superando dificultades que sólo el que conozca lo defectuoso de los códices árabes, y lo difícil de su lectura quando carecen de mociones o vocales, y a veces de puntos diacríticos, podrá justamente apreciar; pero los defectos si había algunos los ha suplido con juiciosas y freqüentes notas, aclarando el texto y corrigiéndole oportunamente quando no había a la mano abundancia de códices con que hacer cotejo, sino sólo el original y una copia muy moderna sacada de él. El autor mahometano no se contentó con tratar muy difusamente del abono de las tierras, punto el más esencial de la agricultura, de la composición y mezcla de los estiércoles, de los tiempos de la siembra, del modo de hacerla, del plantío de los árboles, 
tanto frutales como de otras especies, y de la manera de inxerirlos, sino que extendió su diligencia y cuidado a la cría de ganado vacuno y lanar, mulos, asnos, camellos y caballos, palomas, ánades, patos, pavos reales, gallinas y abejas; y además añadió un tratadito sobre la destilación de aguas olorosas, con otros tan curiosos como útiles; siendo muy apreciable el tratado de veterinaria, y los artículos sobre el caballo y el arte de la equitación, en que hay cosas originales y dignas de saberse. Se ha puesto el texto árabe, que si ha hecho más costosa y abultada la obra, también asegura de la puntualidad en la versión, y desvanece toda sospecha de poca exactitud, vicio que en obras de estos idiomas es imposible conocer si van desnudas del texto original, y así se ha sacrificado el coste en obsequio de la fidelidad. Se hallará en la librería de Ximénez, caños del Peral, a 130 reales en papel y 160 enquadernada en buena pasta: previniéndose que en llegando a 10 juegos los que se compren se rebaxará el 5 por 100 ఎ.

3 Lo era el P. Fr. Antonio do Rosario Baptista Abrantes, el cual era confesor de la Princesa Carlota Joaquina desde enero de 1794, tarea en la que sucedió al español P. Felipe Scio de San Miguel.

4 Fr. Sebastián Sánchez Sobrino, el antiguo compañero de Banqueri y uno de los favorecidos de los Mohedano, hacia quienes después mostró infidelidad, había comenzado a publicar en 1793 unos Sermones varios, Penegyricos, Morales, y Fúnebres. Su autor el P. Fr. Sebastián Sánchez Sobrino, Lector dos veces Jubilado, Dr. en Teología, y Catedrático de Lengua Griega en la Real e Imperial Universidad de Granada, Examinador Synodal de los Obispados de Málaga y Guadix, de la Abadía de Alcalá la Real, y del Arzobispado de Granada, Socio de su Real Sociedad, Ex-Custodio, Ex-Definidor, y Padre de su Provincia del Tercero Orden Regular de N. P. S. Francisco, morador en su Convento de S. Antonio Abad de dicha Ciudad, $y$ en él Regente de Estudios, etc. Tomo I. Con licencia: En Granada en la Imprensa de D. Antonio de Cea, Año de 1793. La publicación de esta serie de pequeños tomos de sermones se mantuvo ininterrumpida hasta el año 1807 y se reanudó en 1814, hasta alcanzar un total de veinte, el último de ellos publicado en 1819.

\section{XIII}

Tortosa 31 de Julio de 1803

Excmo. y Rvdmo. Sr. Arzobispo de Evora Don Manuel del Cenáculo Vilas Boas

Muy Señor mío y más estimado y venerado Padre: No he contestado hasta ahora a la apreciabilísima de V. Excia. de 14 de marzo por el motivo que digo a nuestro Rvdmo. Sousa; y también porque casi al mismo tiempo de recibirla tenía escrito a V. Excia. recomendándole a Don José Chacón, amigo de otro íntimo mío, que me había interesado para ello. Pero en este intermedio tiempo he leído muchísimas veces la suavísima carta de V. Excia. buscando siempre en ella el precioso bálsamo que contienen sus dulces expresiones para templar y sosegar con él la agitación y amargura de mi corazón. ¡Qué bien se hizo cargo V. Excia. de mis aflicciones, cuando su ingeniosa caridad le inspiró el pensamiento de recetarme un antídoto de tanta eficacia! Ciertamente el efecto de la lectura de una carta tan llena de 
cordiales sentimientos, hijos del personal amor que debo a V. Excia. ha sido siempre quedar mi espíritu en una especie de sosiego y tranquilidad inexpugnable; aunque por otra parte me causase la grata agitación de vivísimos deseos de volver a tener la dulce satisfacción de ver a S. Excia. a quien venero y amo más que a Padre, como lo testifica bien la copia de lágrimas que en este momento me vienen a los ojos. ¿Y qué? ¿No me concederá Dios este gusto antes de morir?;Ah! Silos deseos del grande amigo que tengo en el Puerto de Santa María de ser yo trasladado a la Iglesia de Sevilla, entonces sí que podría yo asegurar que quizá antes de tomar posesión pasaría a hacer una visita a quien tanto amo y a quien tantas obligaciones debo. No parece sino que en $V$. Excia. he reunido todos mis particulares amores que ya perdían sus objetos con el fallecimiento de mis Maestros los PP. Mohedanos y de los otros amigos comunes, que han ido desapareciendo después.

El fallecimiento de nuestro ilustre Cornide me fue muy doloroso; y nuestra Academia hizo una considerable pérdida, no obstante que algunos de aquellos compañeros no le han hecho, según me han informado, todo el honor que se merecía. ¿Qué hombres! Y qué desgracia, cuando los que componen un mismo cuerpo no se honran, si es que nos persiguen como pudieran los más encarnizados amigos. No sé qué pensará hacer la Academia de los trabajos de este infatigable literato, así como ignoro también qué hará de los que yo concluí aquí el verano anterior respectivos a la colección de las monedas árabes, de que no tengo más noticias que la que entonces me participó el Sr. Cornide, reducida a que la Academia me daba gracias por ellos. Después nada he vuelto a saber; sino sólo que le sucedió en su empleo de Secretario un Auditor de guerra, llamado Don Joaquín de Flórez, sobrino de Don José Miguel de Flórez, que también fue muchos años Secretario en un tiempo de nuestro común amigo y mi especial favorecedor el difunto Señor Conde de Campomanes.

Por lo que me dice nuestro Sousa veo por qué han quedado sin efecto los celosos deseos de V. Excia. sobre promover la publicación de los Cánones de nuestros Padres antiguos. Pero yo no desespero de que acaso se presente alguna vez ocasión oportuna de promover empresa tan digna. Cuando la Corte pasó por aquí por noviembre no sólo debí muestras de aprecio y favor a muchos de los altos cortesanos, sino también a dos Señores Ministros. El de Gracia y Justicia me ofreció que en llegando a Madrid trataría con el jefe de la Real Biblioteca del asunto glorioso de la Colección Canónica. El otro Señor Ministro de Hacienda, amigo íntimo del anterior, dijo a un compañero mío, el Arcediano mayor de esta Iglesia, que 
yo era el único que podía entender en la preparación de la Colección Canónica árabe. Entonces se verificó lo del poeta: Video meliora proboque. A pesar de esto, he sabido que el primero no ha tratado del asunto con Don Pedro de Silva; y que recordándole cierta persona la necesidad de mi regreso para dar cumplimiento al fideicomiso literario que me dejó el ilustre Casiri, la respuesta fue que no estaba en su mano el disponerlo; y entonces se verificó el deteriora sequor. Tengamos, pues, paciencia, y encomendemos a Dios una causa, que es propiamente suya. Espero en las disposiciones irresistibles de la Providencia que han de quedar burlados los consejos e intenciones contrarias de los hombres.

Ruego a V. Excia. haga presente a su digno hermano mi afectuosa memoria y que me mande lo que fuere de su agrado. Dios me guarde la importante vida de V. Excia. muchos años.

Excmo. y Rvdmo. Señor, B.l.m. de V. Excia. su más afecto y obligado servidor y capellán,

José Banqueri

José-Luis SOTO PÉREZ 